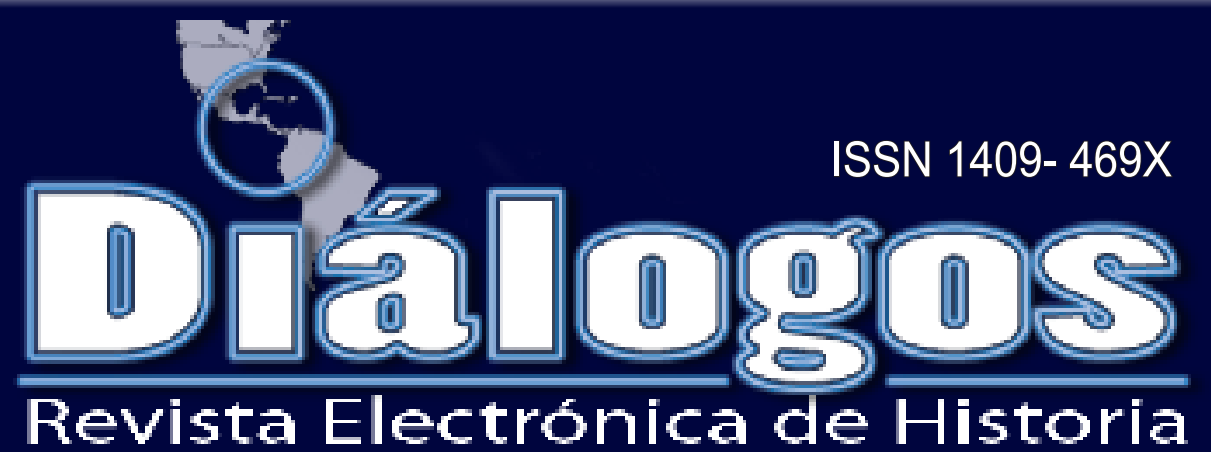

Escuela de Historia. Universidad de Costa Rica Vol. 13 No. 1 Febrero - Agosto 2012

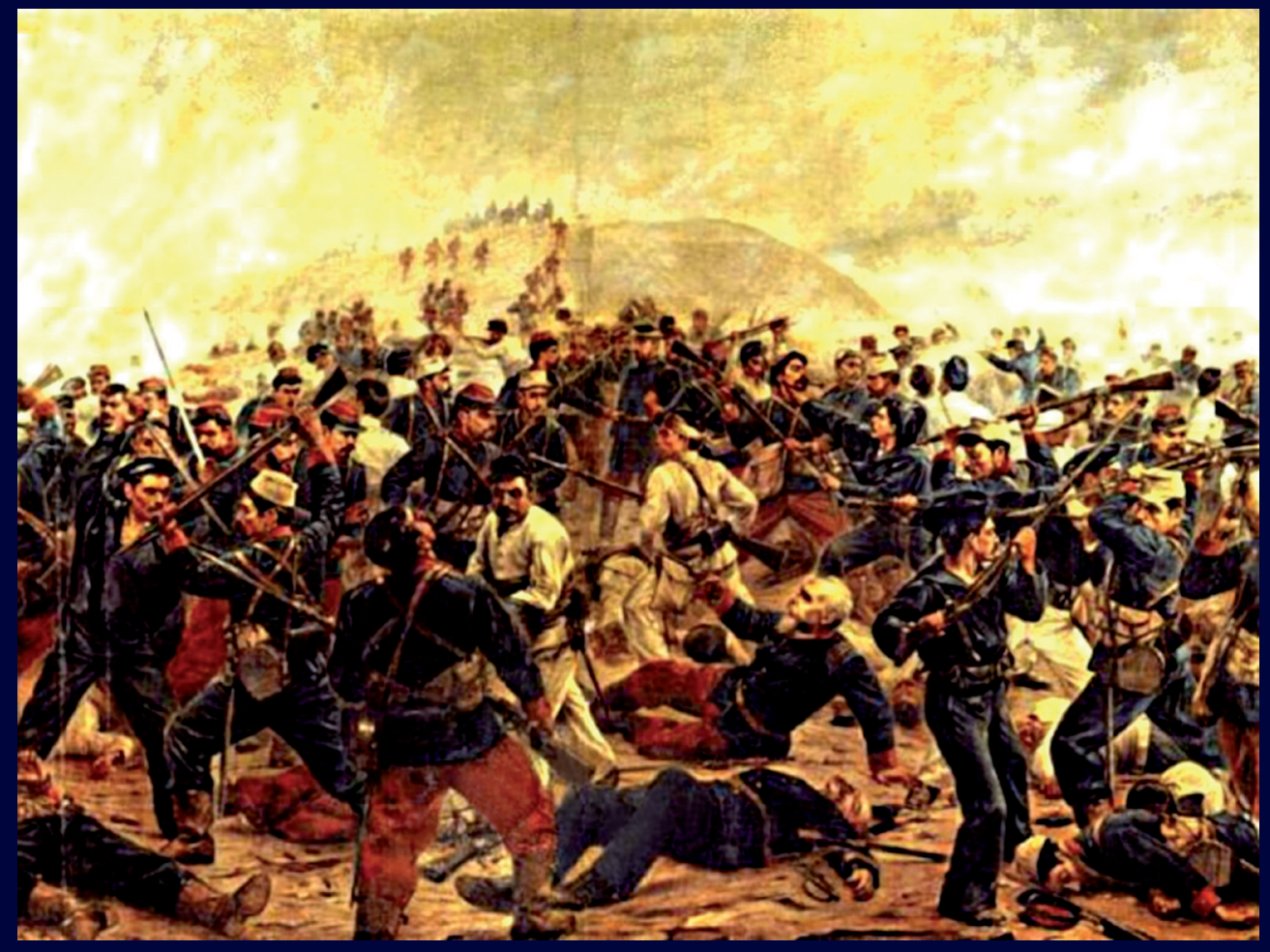

"SOIS VOSOTROS VALIENTES HÉROES. SOMOS NOSOTROS SIMPLES HUMANOS".

LA EXPERIENCIA DE LA GUERRA DEL PACÍFICO EN LOS TESTIMONIOS DE LOS ACTORES

David Angelo Coronado Canales

Director de la Revista: Dr. Juan José Marín Hernández juan.marinhernandez@ucr.ac.cr

Editor académico: Dr. Ronny Viales Hurtado - ronny.viales@ucr.ac.cr Editor técnico: M.Sc. Marcela Quirós G. - marcela.quiros@ucr.ac.cr Asistente: Cindy Chaves U. http://historia.fcs.ucr.ac.cr/dialogos.htm 


\section{Miembros del Consejo Editorial:}

Dr. Juan José Marín Hernández, Catedrático. Director del Centro de Investigaciones Históricas de América Central. Universidad de Costa Rica.

Dr. Ronny Viales Hurtado. Catedrático. Historia Económica y Social. Universidad de Costa Rica. Director de la Escuela de Historia. ronny.viales@ucr.ac.cr

Dr. Guillermo Carvajal. Geografía Humana. Universidad de Costa Rica.

MSc. Francisco Enríquez. Historia Social. Universidad de Costa Rica.

MSc. Bernal Rivas Especialista en Archivística. Universidad de Costa Rica.

MSc. Ana María Botey. Historia de los movimientos sociales. Universidad de Costa Rica.abotey@gmail.com

\section{Miembros del Consejo Asesor Internacional:}

Dr. José Cal Montoya. Universidad de San Carlos de Guatemala.jecalm@correo.url.edu.gt

Dr. Juan Manuel Palacio. Universidad Nacional de San Martín.jpalacio@unsam.edu.ar

Dr. Eduardo Rey. Universidad de Santiago de Compostela.ereyt@usc.es

Dr. Heriberto Cairo Carou. Departamento de Ciencia

Política y de la Administración III - Universidad

Complutense de Madrid. hcairoca@cps.ucm.es

Dra. Rosa de la Fuente. Departamento de Ciencia Política y de la Administración III Universidad Complutense de Madrid rdelafuente@cps.ucm.es

Dr. Javier Franzé. Departamento de Ciencia Política y de la Administración III Universidad Complutense de Madrid. javier.franze@cps.ucm.es

Dr. Jaime Preciado Coronado Departamento de Estudios Ibéricos y Latinoamericanos. Universidad de Guadalajara japreco@hotmail.com

Dr. Gerónimo de Sierra. Vicerrector de la Universidade Federal da Integração Latino-Americana (UNILA) y Departamento de Sociología, Facultad de Ciencias Sociales de la Universidad de la República. geronimo@fcs.edu.uy

Dr. Antonio Palazuelos. Departamento de Ciencia Política y de la Administración III - Universidad Complutense de Madrid. palazuelosa@cps.ucm.es

Dr. Werner Mackenbach. Universidad Potsdam. werner.mackenbach@uni-potsdam.de
Dr. Guillermo Castro. Ciudad del Saber Panamá. gcastro@cdspanama.org

Dra. Natalia Milanesio. University of Houston.

nmilane2@Central.UH.EDU

Dr. Ricardo González Leandri. Consejo Superior de Investigaciones Científicas - España.

rgleandri@gmail.com

Dra. Mayra Espina. Centro de Estudios Psicológicos y Sociológicos, La Habana. mjdcips@ceniai.inf.cu

Dra. Montserrat Llonch. Departamento de Economía e Historia Económica Universidad Autónoma de Barcelona montserrat.llonch@uab.es

Dra. Estela Grassi. Universidad de Buenos Aires. estelagrassi@gmail.com

Portada:

Óleo de Juan Lepiani titulado Batalla de Arica (1880-Museo de los Combatientes de Arica) : Volumen 13- No. 1, artículo 2 "Sois vosotros valientes héroes. Somos nosotros simples humanos"... de David Angelo Coronado Canales. Fuente: http://members.tripod.com/ Guerra_del_Pacifico/ARICA3. html

"Diálogos Revista Electrónica de Historia" se publica desde octubre de 1999.

\section{Diálogos está en los siguientes repositorios:}

Dialnet

http://dialnet.unirioja.es/servlet/revista?tipo_busqueda=CODIGO\&clave_revista=3325

Latindex

http://www.latindex.unam.mx/larga.php?opcion=1\&folio=12995;

REDALYC

http://redalyc.uaemex.mx/src/inicio/FrmBusRevs2.jsp?iEdoRev=2\&cvepai=11

LANIC

http://lanic.utexas.edu/la/ca/cr/indexesp.html;

Repositorio de Revistas Universidad de Costa Rica http://www.latindex.ucr.ac.cr/

Directorio y recolector de recursos digitales del Ministerio de Cultura de España

http://roai.mcu.es/es/inicio/inicio.cmd

DOJAC Directory of open access \& Hybrid journals http://www.doaj.org/doaj?func=byTitle\&hybrid=1\&query=D

Biblioteca de Georgetown

http://library.georgetown.edu/newjour/d/msg02735.html

Asociación para el Fomento de los Estudios Históricos en Centroamérica

http://afehc.apinc.org/index.php?action=fi_aff\&id=1774 
Universidad de Saskatchewan, Canadá

https://library.usask.ca/ejournals/view/1000000000397982

\section{Monografias}

http://www.monografias.com/Links/Historia/more12.shtm

\section{Hispanianova}

http://hispanianova.rediris.es/general/enlaces/hn0708.htm

Universidad del Norte, Colombia

http://www.uninorte.edu.co/publicaciones/memorias/enlaces.html

Universidad Autónoma de Barcelona

http://seneca.uab.es/historia/hn0708.htm

Repositorio Invenia - Gestión del Conocimiento

http://www.invenia.es/oai:dialnet.unirioja.es:ART0000086144

Enlace Académico

http://www.enlaceacademico.org/biblioteca/revistas-en-formato-digital-centroamerica/

\section{Electronic Resources}

http://sunzi1.lib.hku.hk/ER/detail/hkul/3987318

Revistas académicas en texto completo

http://web.prw.net/ vtorres/

\section{Diálogos se anuncia en las siguientes} instituciones y sitios académicos:

\section{Maestroteca}

http://www.maestroteca.com/detail/553/dialogos-revista-electronica-de-historia.html

\section{Biblioteca de Georgetown}

http://library.georgetown.edu/newjour/d/msg02735.htm
Asociación para el Fomento de los Estudios Históricos en Centroamérica

http://afehc.apinc.org/index.php?action=fi_aff\&id=1774

Universidad de Saskatchewan, Canadá

https:/library.usask.ca/ejournals/view/1000000000397982

\section{Monografias}

http://www.monografias.com/Links/Historia/more12.shtml

Hispanianova

http://hispanianova.rediris.es/general/enlaces/hn0708.htm

Universidad del Norte, Colombia

http://www.uninorte.edu.co/publicaciones/memorias/enlaces.html

\section{Universidad Autónoma de Barcelona}

http://seneca.uab.es/historia/hn0708.htm

Repositorio Invenia - Gestión del Conocimiento http://www.invenia.es/oai:dialnet.unirioja.es:ART0000086144

\section{Enlace Académico}

http://www.enlaceacademico.org/biblioteca/revistas-en-formato-digital-centroamerica/

\section{Electronic Resources}

http://sunzi1.lib.hku.hk/ER/detail/hkul/3987318

Revistas académicas en texto completo http://web.prw.net/ vtorres/

La revista electrónica Diálogos es financiada por la Vicerrectoría de Investigación de la Universidad de Costa Rica
Citado en Dialnet - Latindex-

Redilac- Directorio y recolector de recursos digitales del

Ministerio de Cultura de España cc) creative 



\title{
"SOIS VOSOTROS VALIENTES HÉROES. SOMOS NOSOTROS SIMPLES HUMANOS". \\ LA EXPERIENCIA DE LA GUERRA DEL PACÍFICO EN LOS TESTIMONIOS DE LOS ACTORES
}

\author{
Palabras claves \\ Percepción, espacio, comercio, Índico, Pacífico.
}

\section{Keywords}

Perception, space, trade, Indian Ocena, Pacific Ocean.

Fecha de recepción: 26 julio de 2011 - Fecha de aceptación: 6 noviembre 2011

\begin{abstract}
Resumen
El trabajo que presentamos es una análisis pormenorizado de la evolución espacial que el hombre europeo desarrolló de los grandes nódulos comerciales del sudeste asiático. Partiendo de un análisis teórico, y analizando 250 mapas, hemos secuenciado el proceso de percepción geográfica y mercantil entre 1500 y 1800 . Por ello hemos realizado dos cómputos: el peso cartográfico absoluto de los grandes puertos y, en segundo lugar, el peso cartográfico relativo. Ello nos permite saber que era lo que se "percibía" y determinar el "ritmo" de la evolución de la percepción espacial.
\end{abstract}

\begin{abstract}
The work we are presenting is a detailed analysis of developments in space as men of the great European developed nodules trade in Southeast Asia. Based on a theoretical analysis, and analyzing 250 maps, we have sequenced the process of perception and geographic market between 1500 and 1800. We have conducted two computations: mapping the weight of all the major ports, and secondly, the relative weight mapping. This lets us know that was what was "perceived" and determine the "pace" of changing the perception of space.
\end{abstract}




\section{"SOIS VOSOTROS VALIENTES HÉROES. SOMOS NOSOTROS SIMPLES HUMANOS".}

LA EXPERIENCIA DE LA GUERRA DEL PACÍFICO EN LOS TESTIMONIOS DE LOS ACTORES*

David Angelo Coronado Canales

\section{LA GUERRA. UNA PROBLEMÁTICA DE MÚLTIPLES ANÁLISIS}

La Guerra del Pacífico fue un conflicto delicado y que llevó a la población chilena que participó a abandonar sus fronteras en aquella época y a buscar la victoria en el mismo corazón de la Alianza de Perú y Bolivia.

Dentro de las principales problemáticas de la Guerra como un problema social más profundo. Un concepto central que se trata al momento de hablar de un conflicto es la idea de nación y del sentimiento nacional que esta identidad encierra. Si bien estos temas han sido tratados en plenitud por múltiples autores (Gellner, Hobsbawm, Anderson, entre otros) que han visto el concepto constructivo e histórico del sentimiento nacional y de la idea de "comunidad" nacional, la nación como concepto histórico - y en este lo entendemos no como categoría de estudio histórico, sino como proceso que posee implícitamente una historicidad- conlleva a comprender los elementos constructivos de este sentimiento y de cómo se configuran el cambio desde una comunidad implícitamente pre-moderna a una moderna y de carácter burocrático, estatal y racionalizado 1 .

El caso de la identidad nacional ha tenido en la Historiografía nacional del s XX un claro ejemplo en el concepto de "El estado como articulador de la nacionalidad"; concepto planteado por el historiador Mario Góngora y que la Historia nacional de tendencia marxista y neo-marxista (otra denominación para la tan famosa nueva Historia social chilena) ha puesto en dudas o al menos criticado con fuerza.

La idea de una homogeneidad en el discurso histórico nacional plantea principalmente que nuestro país se ha construido de forma "ordenada, tranquila" y sin pormenores mayores ya que sus integrantes (los chilenos) han representado un pueblo que se ha construido en torno al "Estado" como matriz de la nacionalidad".

$\mathrm{Si}$ algo tenemos claro en cuanto al estudio de la nacionalidad chilena en el s. XIX es la necesidad de sistematizar un trabajo mucho más profundo en cuanto al aporte de teórico de orden revisionista. Estas nuevas corrientes han potenciado el estudio de los orígenes de la nación y si bien no es el meollo de nuestro artículo, resulta indispensable partir de "algo" para establecer el contexto en el cual se implementará la Guerra del Pacífico³. 
Siguiendo a William Sater, él plantea la inexistencia de una unidad nacional en el Chile decimonónico. Un elemento que ya hemos puesto de manifiesto es la aprehensión por parte de los sectores populares del ideal nacional. Julio Pinto postulaba que "desde mucho antes del estallido de la guerra es posible detectar entre esos trabajadores [del salitre] una serie de conductas que al menos a primera vista podrían decodificarse como 'nacionalistas', y que podrían llevar a considerar bajo una nueva óptica las imágenes contrapuestas que hasta aquí se han señalado"4. Esto debe enmarcarse en un debate fuerte entre las ideas esencialista de la identidad del mundo popular (tanto en el concepto de clase como en el de patria) y del cual Julio Pinto soluciona (al igual como Florencia Mallon para el caso del México y el Perú decimonónico) por medio de una relación dialéctica entre ambos conceptos.

El problema de la nacionalidad popular no es menor en este sentido ya que el análisis del trabajo de Julio Pinto y otros como el de Cecilia Osorio. Esta última señala que las relaciones de nacionalidad poseían un importante contenido de violencia. En su trabajo puntualiza cómo la violencia del mundo salitrero del s. XIX, tiene en su cotidianeidad un importante influjo causado por los conflictos entre nacionalidades distintas. Sin embargo esta misma autora en un trabajo posterior señala que dicha hipótesis no parece sostenerse ${ }^{5}$.

El problema del nacionalismo tiene una relación importante con la construcción histórica que como "comunidad nacional hemos acerca de nuestro pasado Republicano, en donde la denominada "Historia oficial" ha cargado con una

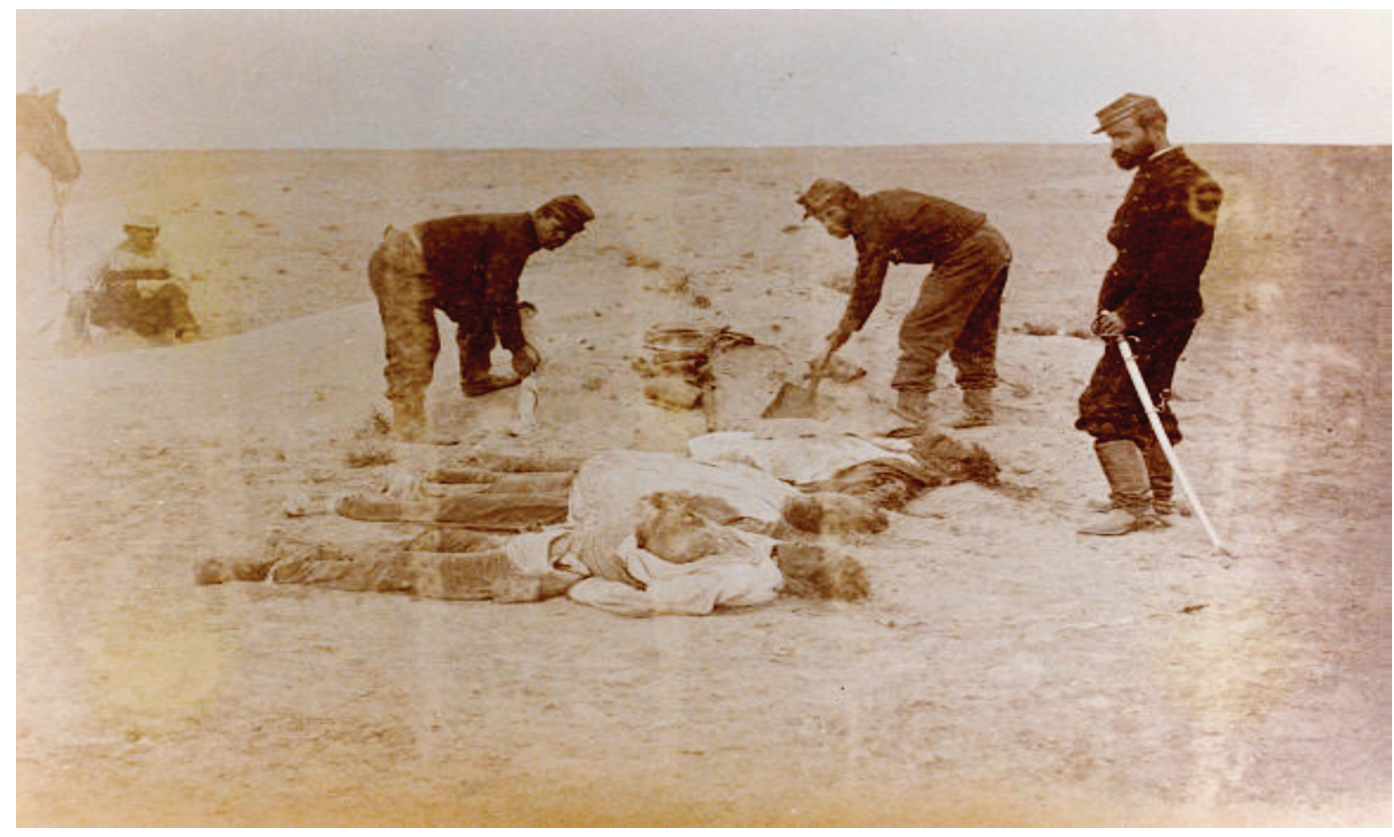

Figura 1. Faena de Sepultación de los muertos tras la Batalla de Tacna. Fuente: http://www.laguerradelpacifico.cl/Fotografias/Guerra\%20en\%20fotos.htm 
mitificación de el pasado que encierra primero, en una sola unidad (cuasi ontológica) a todos los chilenos y segundo, una especie de esencialismo guerrero-bélico de nuestra sociedad 6 .

Julio Pinto al hablar de la contradicción entre los elementos - o coordenadas- culturales desde arriba y la asimilación de estos por el mundo popular y que eran conectados o convivientes con discursos autónomos desde abajo así es como "el lenguaje en que se comunicaban, las creencias religiosas que profesaba, y en general los referentes culturales que le daban sentido a su existencia compartían una serie de rasgos con los de una elite"

La transformación socio-cultural que tendrá ésta elite, que en un inicio fue poco sofisticada y cosmopolita, mucha más homogeneizada en cuanto a su relación socio-cultural con el pueblo ${ }^{8}$; debido a la constante separación de la clase dirigente del segmento popular. En otras palabras su oligarquización causaría quiebres a fines del s. XIX que la alejarán de los problemas del mundo popular.

En este sentido no existen mayores momentos de unidad, de vitalidad nacional o de surgimiento de "mitos históricos" que en las Guerras. Los conflictos bélicos como matrices de sentido nacional son a nuestro juicio un poderosísimo articulador de unidades (reales o ficticios) que pudieron haber sido utilizados por las clases dirigentes para unir a un país que tras la crisis económica de los años setenta estaba al borde de un colapso intra-elite 9 .

La construcción del discurso nacional entramó en sus "hilos" una imagen simplificada de lo que fue la Guerra y por ende de lo histórico dejando las experiencias de los actores reducidas a simples imágenes de lo que ellos querían que fuera la representación imaginaria del chileno.

La Historiografía liberal y conservadora ha unido fuerzas en mostrar a los hombres (de todas las clases sociales) que se enfrentaron en la Guerra como valientes arquetipos de la nacionalidad chilena ${ }^{10}$, des-historizaciónes ejemplares que vuelven un conflicto histórico en un mito maniqueo, que representa en sus actores, elementos resumidos del bien (chileno) y del mal (peruanos / bolivianos) ${ }^{11}$ y que le restan historicidad al sujeto que peleó, luchó y sufrió en el campo de batalla.

En este sentido la reconstrucción histórica de la Guerra del Pacífico han reflejado en los testimonios que hemos podido tener a mano, la real sensación sobre la Guerra que muchos de los soldados tuvieron. Estos soldados que el discurso oficial mostró como grandes y valerosos héroes, en efecto tuvieron miedo y no se diferenciaban en demasía a los soldados peruanos o bolivianos que combatían -conscientes de su "nacionalidad" o forzados por uno u otro motivo- a combatir conciente o inconscientemente por algo "mayor" a ellos.

Lo importante en este caso es que las guerras - como la Guerra del Salitre- las hacen y combaten seres humanos. Esa es la intención del presente artículo y lo que intentamos mostrar con la investigación de los testimonios. 
En primer lugar revisaremos el testimonio de algunos testigos y actores del Combate Naval de Iquique, posteriormente los de los soldados Alberto del Solar, Arturo Benavides, participantes de la Guerra del Pacífico y los relatos de Hipólito Gutiérrez, Abraham Quiroz (estos dos últimos soldados rasos) y anexamos el testimonio de Evaristo Sanz y José Clemente Larraín que complementan lo ya investigado anteriormente.

\section{SIN FUENTES NO HAY HISTORIA. EL TESTIMONIO COMO FUENTE EN LA HISTORIOGRAFÍA ACTUAL.}

Pero antes de ingresar al trabajo histórico propiamente tal, es importante trabajar el problema de las fuentes. Si bien este es un asunto metodológico (no vamos a trabajar problemas epistémicos sobre la naturaleza de la Historia), ciertamente el trabajo sobre la "materia prima" de la Historia es importante de tratar.

En un primer momento el texto (algo clásico y no muy actualizado) de Metodología de la Historia de Topolsky, nos habla de la Teoría del conocimiento basada en fuentes ${ }^{12}$, como una posibilidad metodológica de interpretar el pasado y analizarlo desde (y por medio) de fuentes documentadas, escritas principalmente e intencionales.

Dentro de su debate con respecto a las fuentes está la idea de estas como "productos" intencionales que nos permiten conocer el pasado (reliquias) o interpretar cognoscitivamente el pasado (y sus intenciones) ${ }^{13}$. Si bien en este sentido se postergan y se dejan de lado una serie de fuentes no-intencionales, plantea una definición primaria que nos acerca el problema ${ }^{14}$.

En términos concretos el desarrollo de la Historiografía actual y el realce del testimonio es una herramienta útil y necesariamente debemos abordarla en nuestra investigación.

En una clasificación clásica el testimonio escrito se ha clasificado como un tipo de fuente directa con destinatario y escrita ${ }^{15}$. Esta clasificación nos revela la ventaja que podría tener este tipo de fuente para un estudio histórico basado en asociar la Historia a lo que los testimonios (en nuestro caso de los soldados) evidenciaron y sufrieron en la Guerra del Pacífico ${ }^{16}$ y que en términos de las corrientes más estructuralistas (Annales, escuela serial norteamericana) serían fuentes obsoletas y sin ninguna fortaleza en cuanto a su estudio.

Una vez establecido el problema de las fuentes históricas testimoniales es preciso señalar el (o los) problemas que dichas fuentes presentan a un tipo de Historia cientificista. Para ello uno de los más importantes historiadores del siglo XX, Marc Bloch, nos avisa de la importancia que tiene la "crítica" de las fuentes como forma de superar la ingenuidad positivista y la credibilidad frente 
a las fuentes, sobre todo aquellas que como los testimonios tienen la "misión" de transmitir información.

Para Bloch los testimonios, nos entregan la seguridad de una datación cronológica que el estudio "pre"-histórico no posee, pero otorga otros dramas metodológicamente hablando ${ }^{17}$.

Si bien este historiador nos previene de la ingenuidad con las fuentes nos avala el estudio de fuentes testimoniales porque nos ayudan a combatir la "esclerosis irremediable"18. Pero en el estudio de la Historia "entre líneas", aquella donde es más preponderante que lo que concientemente el (o los) autores quisieron decir, cobra importancia lo que nos dicen sin haberlo querido hacer. En este sentido el cuestionamiento de las fuentes (y todo el método que eso implica) deja entrever la necesidad de trabajar metodológicamente, los testimonios no para rescatar "el valor y heroísmo", que concientemente exponen en sus crónicas y testimonios, sino que sus miedos y aquello que quizás no deseándolo, al no omitirlo nos permite entender su pasado y su contexto. Aquello, Bloch lo resume magistralmente:

"Desde el momento en que ya no nos resignamos a registrar [pura] y llanamente las palabras de nuestros testigos, desde el momento en que nos proponemos hacerlos hablar, [aun contra su voluntad] más que nunca se impone un cuestionario. Tal es efectivamente la primera necesidad de toda investigación histórica"19. El hacer las preguntas correctas en el análisis de testimonios es fundamental. Nuestro énfasis es ese principalmente.

La idea testimonial de Bloch, sin embargo se engloba en lo que es la postura epistemológica de San Agustín y el problema de la Aporía del tiempo. La idea del triple presente y el presente del pasado como aquellas "huellas" o vestigios en el ahora, que sobreviven el paso del tiempo y nos permiten adentrarnos en el estudio de un tiempo pretérito ${ }^{20}$.

Es por esto que Le Goff señalara "Su única habilidad [del historiador] consiste en extraer de los documenti todo lo que contienen y en no agregarles nada que allí no esté contenido. El mejor historiador es aquel que se mantiene lo más próximo posible a los textos" ${ }^{21}$. Esta cita nos hace ver que al igual que Marc Bloch su visión de la historia es científica y del historiador como un científico, objetivo que debe observar su objeto (la Historia) sin volcar ni sus interpretaciones ni sus valores.

Para Le Goff están los monumentos "Herederos del pasado" los cuales tiene dos sentidos de término:

a) Obra arquitectónica o escultura obra de arte, material que busca perpetuarse como conmemoración, b) Monumento funerario busca transmitir el recuerdo tras la muerte.

Estos dos puntos señalados, tienen en común perpetuar de forma voluntaria e involuntaria a una sociedad (legado de la memoria colectiva). 
Los documentos estaban considerados como prueba histórica; aunque en realidad, según Le Goff, es una elección. No es fiable como verdad absoluta (refiriéndose a lo que realmente sucedió), Pues tiende a señalar que la valoración del documento (texto)* que se tenia en el s. XIX es una visión muchas veces más patriótica en el sentido de la historia que la del de un carácter científico ${ }^{22}$ Las publicaciones de textos recopilatorios (fuentes) marca el triunfo del documento del positivismo. La idea de documentos se ha ido ampliando, y es Le Goff quién en su libro sintetiza más bien de forma clara que no es sólo documento "lo escrito" y que de esa forma siguiendo a Lefebvre señala que "no hay relato histórico sin documentos".

La ampliación del término Documento, es una adaptación a las necesidades de un conocimiento histórico más cercano a la ciencia, por ende todo "vestigio" del pasado es utilizable. Ya no es una mera acumulación de datos escritos ${ }^{23}$ y donde los estudios de filología han entregado una visión más critica de los documentos buscando ver su veracidad (tanto con respecto a lo que narran como a que su datación sea real).

Los testimonios por ende cumplen una función, pero ¿serán acaso en el paradigma actual de la Historiografía, una fuente útil? A nuestro juicio sí. Ya vimos los resquemores de las corrientes históricas del siglo XX hacia este tipo de fuentes, pero sin embargo algunas posturas como la de la Historia del Tiempo Presente o la Historia oral (testimonial) han puesto en realce el estudio con y por medio de los testimonios ${ }^{24}$.

En nuestro trabajo hemos de entender al testimonio como una fuente rica en subjetividades que son permitidas a rescatar en nuestros trabajos historiográficos. En primer lugar nos tomaremos de una corriente histórica que usa testimonios en la actualidad: La Historia social.

La Historia oral (testimonios) no busca sólo afrontar la verdad histórica propiamente tal, sino además las impresiones y subjetividades de los actores históricos para re-construir la "memoria" histórica ${ }^{25}$.

El problema de la verdad y cientificidad de la Historia es un elemento complejo y que atenta (y atentó con fuerza) al uso de las fuentes escritas para la re-construcción del pasado como "inconciente" 26 . En este sentido la Historia cuantitativa (francesa, inglesa y/o norteamericana) postergó el valor de las fuentes escritas a un tercer plano o quizás más allá27.

Pero dejaremos abierto el tema de la verdad y la objetividad, para darnos a entender con otro elemento de la Historia. La subjetividad y el carácter simbólico de las fuentes. Para Ronald Fraser la subjetividad de la Historia oral es definible como "los procesos mediante los cuales los individuos expresan su sentido de sí mismos en la historia" ${ }^{28}$. Si bien la argumentación de Fraser busca justificar la Historia oral, nos lleva a un plano de las mentalidades, la subjetividad y de lo cultural que es abarcable, pesquisable por medio de los elementos subjetivos (y agregaríamos vástagos 
de la memoria del pasado) de un siglo donde ya la Historia oral es imposible como método por problemas temporales irresolubles. El silgo XIX (y más atrás en el tiempo con mayor razón) donde los procesos y sus "actores" no están vivos. En otras palabras, si queremos descubrir la información subjetiva de la memoria (individual y/o colectiva) que la entrevista y la Historia oral nos otorga, para tiempos donde los actores históricos no están presentes, el testimonio escrito (diarios, crónicas, cartas personales etc.) son la fuente más importante para solucionar el problema.

En este punto queremos eso sí, enfatizar (nuevamente) la des-sacralización del testimonios y de las fuentes escritas como "la" gran fuente de la Historia. La ingenuidad positivista fue superada y no pensamos en re-caer en idealizaciones.

Por eso el juicio de autores como Federico Suárez cuando dicen que "lo que diga un escrito siempre será más rico que lo que diga una piedra, una moneda o una fotografía" ${ }^{29}$, no nos resulta satisfactorio, ni aportan al desarrollo de la Investigación. Nada más alejado de nuestros conceptos.

El estudio histórico del yo, de la auto-representación y de las sensaciones y emociones pasa necesariamente por utilizar fuentes donde dicho fenómeno se desenvuelva y quede reflejado en alguna "huella" del pasado, y ahí, los testimonios son la fuente de autorepresentación estereotipada por excelencia ${ }^{30}$.

Sin querer señalar una teoría nueva sobre el testimonio, si es necesario enfatizar que es la memoria como una manía excesiva que teme el olvido ${ }^{31}$. La Historia y la memoria (como problema epistemológico), espacio dialéctico entre el recuerdo y el olvido, sitúa a la Historia como la reconstrucción del pasado ${ }^{32}$. De esta manera ¿cómo puede la Historia apoderarse de ese espacio vivo? A través de los testimonios escritos y presentes en lo que Jacques Le Goff, despectivamente llamaría los documentos-monumentos que muchas veces son menospreciados, pero que hemos visto poseen una riqueza única. ¿Cómo conciliar este espacio siempre presente de la memoria con el re-construir el pasado? Difícil cuestión a tratar.

Para esto la memoria es un mecanismo "para sentirnos relativamente confortables con nuestras vidas. Algunas memorias son contradictorias, dolorosas. No fácilmente concuerdan con nuestra identidad presente, o contienen traumas que nunca fueron resueltos". Independiente de si es un problema subjetivo sicológico (intimista) o colectivo ${ }^{33}$. Nuevamente señalamos ¿cómo podemos historiar, investigar este tipo de fenómenos en el siglo XIX? Los testimonios son la solución perfecta para nuestro propósito.

Finalmente, memoria, recuerdo, olvido, verdad, subjetividad son todos conceptos que son importantes a la hora de trabajar el mundo de la Historia. Bajo el paradigma actual de la Historia, el testimonio tiene una validez importante siempre y cuando se le realce su importancia, pero tampoco se le coloque en el nivel (ingenuo) que el positivismo lo tenía. 


\section{LOS TESTIMONIOS. LA HISTORIA OFICIAL PUESTA A PRUEBA EN LOS ACTORES DEL CONFLICTO. EL CASO DEL COMBATE NAVAL DE IQUIQUE}

Uno de los eventos más recordados y ejemplificador del nacionalismo chileno fue, sin duda el afamado combate Naval de Iquique.

Mucho de lo que se recuerda es el heroísmo que mostraron los marineros chilenos - resumida en el acto del capitán Arturo Prat- y lo desigual del combate entre el buque chileno (Esmeralda), una frágil corbeta de madera y el acorazado peruano Huáscar.

Sin embargo todo esto, hemos deseado rescatar la otra cara del conflicto mostrando quizás obviedades de lo que implica un conflicto bélico, pero que en la reconstrucción histórica que se hace del combate, no deja espacios a estos elementos

El relato del cirujano de la Esmeralda Dr. Cornelio Guzmán nos narra las vivencias de los marinos chilenos en medio del combate y la verdadera carnicería que se afronta, debido al fuego desde tierra y por el mar que recibía la Esmeralda y que les causaba serias bajas,

"El sitio en que estábamos nos obligaba a permanecer en la mas completa ignorancia de todo lo que pasaba en cubierta. Solicito entonces permiso para ir a hablar con el comandante. Esta vez se le ordenó que tomara un rifle. Mas tarde el contador fue llamado para atender a la destrucción de la correspondencia y de toda la documentación. De este modo mi personal quedo reducido en dos valores menos" ${ }^{34}$

El primer espolonazo envió a un gran número de chilenos al agua siendo uno de ellos el Cirujano Guzmán quien narra que al ser rescatado por el Huáscar logró enterarse de la muerte de Prat al verlo en la cubierta del Huáscar,

"Me pareció que mi buque partía por mitad, y una ola inmensa nos cubrió y sumergió. No puedo decir hasta que profundidad hemos llegado. Yo, que soy gran nadador, nade con el intento de llegar a la superficie y de salir de la oscuridad en que me encontraba; luego vi una luz y una claridad. Miro a mí alrededor y veo que varias cabezas emergían casi al mismo tiempo, y también aparecían flotando una gran cantidad de tablones rotos, coyes y tinas de combate; sirviéndonos todo esto de ayuda para no sumergirnos nuevamente. Los sobrevivientes formábamos un circulo que permitía vernos las caras y reconocernos (...) Conducidos al Huáscar, y mientras desfilábamos los oficiales a la cámara del comandante Grau, vimos tendido sobre cubierta el cadáver de Prat" ${ }^{35}$

Otro relato por medio de una carta es el del Teniente Francisco Segundo Sánchez. Por lo que leemos de su relato su puesto era de vital importancia - siendo el tercer oficial después de Prat - ya que el mismo cuenta que una vez muerto Prat (tras el abordaje) el Teniente Luis Uribe tomó el mando de la Esmeralda y Sánchez el puesto de Uribe. Al relatarnos el abordaje lo hace con una frialdad y un realismo extraordinarios, 
"Creo que de los 200 hombres que formaban nuestra tripulación no hubo uno solo que no dijera al ver al Huáscar, que a toda fuerza venía hacia nosotros, estamos perdidos. Por fortuna, nuestro comandante logró maniobrar de tal suerte que lo recibimos por la aleta. En esos supremos momentos toda la gente estaba en sus puestos de combate" 36

El relato del segundo abordaje posee una realidad que no es en ningún momento matizada de elementos supra-históricos (tan clásico de la re-construcción posterior al combate), pero no sin destacar el arrojo, valentía de Serrano y su necesaria inmortalización:

"En esta ocasión, es decir, en el momento del choque, veo a Serrano que se dirige a proa, i al acercárseme me dice: amigo Sánchez estamos fregados, i continuó su camino. Grande fue mi sorpresa cuando lo veo saltar a la cubierta del Huáscar con diez a doce hombres que también murieron" 37

Interesante es ver como finaliza su relato sobre el hundimiento y los intentos por sobrevivir por parte de los marinos chilenos.

"Un momento después, una nata de cabezas humanas flotaba en la superficie i cada uno trataba de agarrarse a algún coi o pedazo de maderas, de los que había muchos [...] Repentinamente me encontré atraído por el remolino i la atracción que formó el buque al sumergirse. Tragué bastante agua i recuerdo bien que en esos instantes me consideré perdido, por creer que la fuerza del agua me arrojaría dentro de la cámara alta. En estos apuros toqué algo i agarré bien. Me pareció ser algún cuerpo. Inmediatamente reconocí que era un coi. Este gran recurso me llevó luego a la superficie. ique felicidad es volver a la luz!"38

De estos relatos constatamos que la agonía se fusiona con la valentía y que así como nuestra Historia a podado los relatos no sólo ha sacado el sufrimiento de las masas de marinos, soldados y sólo reduciéndolo a arquetipos, al leer estas páginas constatamos que no hay en ellos simplismo sino que la complejidad y contradicción a veces de la historicidad del hombre y de su potencialidad de significarse en la Historia ${ }^{39}$.

\section{ARTURO BENAVIDES. LA CRÓNICA DE UN HISTORIADOR- FUENTE}

Arturo Benavides, oficial del Ejército de Chile escribió algunas de las experiencias de su servicio durante la Guerra del Pacífico y cuales fueron las características del soldado chileno visto desde la oficialidad y desde el sector elitista del Ejército.

Lo importante en esta crónica, como en las demás, tiene que ver con los elementos de cotidianeidad que se extrapolan de sus relatos ya sean escritos en el momento o en redacciones posteriores de sus "recuerdos" de la Guerra.

La visita de la oficialidad a los enfermos diariamente era parte de su rutina. Benavides revela una característica interesante- no nueva- pero al menos que se 
omite en la imagen del héroe que se enseña; "Al poco haber ascendido me correspondió ese servicio con un oficial que era amigo de mi familia. La mayor parte de los enfermos que visitamos lo eran de enfermedades vergonzosas" ${ }^{40}$.

Este tipo de comportamientos eran muy típicos de los ejércitos dados las condiciones del clima, del terreno y el carácter de "enganchados" de muchos de los soldados participantes. Carlos Donoso y Juan Ricardo Couyoudjian señalan que "la lejanía del hogar, la disciplina impuesta en el cuartel, la rigidez de los horarios el tedio, tenían como contrapartida las tentadoras ofertas que ofrecía la ciudad, que rápidamente se acondicionó a las necesidades de soldados y oficiales. Abundaban allí las casas de juego, prostíbulos, locales de expendio de alcohol, y otro tipo de entretenciones" 4 .

La desolación y la desesperanza que pudieran sufrir los soldados es un elemento que va de la mano con las diversiones posibles. La reducción del consumo de alcohol, la remisión de los sueldos de los soldados de forma íntegra a sus familias para evitar que lo gastaran en diversiones poco sanas y moralmente dudosas, contribuía a aumentar los deseos de deserción en la tropa, y que se agregaron al clima indómito y desértico ${ }^{42}$.

En algunos casos la agonía llevaba al extremo de terminar con la propia vida:

“ $¡$ los [padecimientos cruzando el desierto] que ellos pasaron no pudieron ser aliviados por nadie!...

Se aseguraba por esos días en el campamento que dos soldados se habían suicidado durante la marcha, enloquecidos por la sed (...)

Creo que esto no podrá comprobarse oficialmente; pues el fallecimiento por múltiple consideraciones debe haberse explicado como natural"43

Mientras se encontraban acampando en Yaras, la vida cotidiana de la Guerra en el ejército era compleja. Los problemas del aseo y la limpieza son asuntos típicos de todo acontecer y que no pueden estar ajenos a una campaña militar por el desierto - aumentados con los problemas de la vida del siglo XIX, movilización, comunicaciones etc.- y que Benavides nos relata:

“ Mortificaba también, especialmente a los oficiales, el forzoso desaseo personal, pues no había cómo cambiar la ropa interior por haber quedado a bordo el equipaje, y no haberse desembarcado todavía.

A poco la tropa fue invadida por legiones innumeras de piojos, no obstante haberse organizado un servicio para lavar la ropa, permaneciendo desnudos mientras la lavaban y se secaba" 44

Benavides muestra una imagen más profunda del soldado chileno, cuando refleja los temores, las formas de convivir o la cotidianeidad, el simple acto de la escritura de cartas a sus seres queridos y que a Benavides le tocó hacer mucho por saber escribir. Este relato muestra la otra parte de la vida militar y deja aflorar los sentimientos de lo que es en realidad sólo seres humanos 
"Por las confidencias que me hacían pude aquilatar los sentimientos de esos bravos muchachos; rudos exteriormente cual ásperos guijarros desprendidos de duro granito, y con sentimientos tan sencillos, nobles y delicados, que sin esfuerzos, si la ocasión se presentaba, podrían llegar al más alto grado de heroísmo, sin sospechar que ejecutaban acción meritoria" 45

Esto queda fuertemente plasmado en un ejemplo de carta de un joven de 22 años, mandada a redactar para su madre y que cuenta lo siguiente; "si en la batalla que vamos a tener, la largo, sepa mamita que para Ud. Será mi último pensamiento, y que al dar la última boquiá, tendre bien agarrao el escapulario de la Virgen del Carmen como me lo ha recomendao, pa de un salto treparme al cielo"46.

Otro aspecto que refleja la crónica de Benavides es la forma de afrontar las diversas luchas. Las expresiones con las cuales se refieren a las batallas, cuáles son sus sensaciones y apreciaciones acerca del conflicto bélico en sí.

En estos relatos refleja las impresiones acerca del soldado chileno, por medio de las opiniones y descripciones que hacía Benavides de las batallas es lo que nos da una perspectiva, por ejemplo durante la famosa "toma del morro de Arica" 47 .

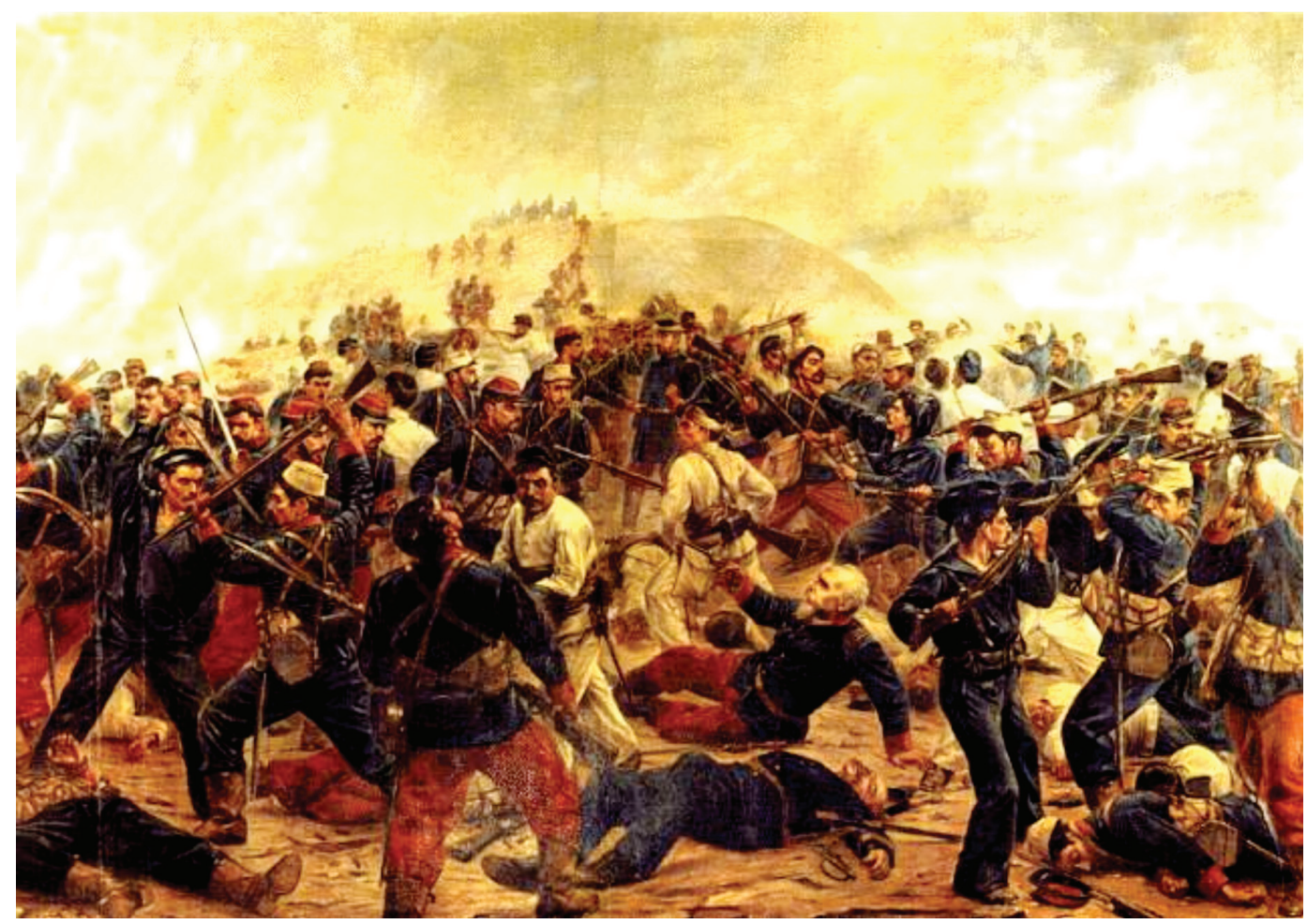

Figura 2. Óleo de Juan Lepiani titulado Batalla de Arica.

Fuente: http://members.tripod.com/ Guerra_del_Pacifico/ARICA3.html

Un elemento a destacar es la diferencia de visión de cómo afrontar el combate. La lucha frente a frente y en el combate "caballeresco" que buscaban plantear los 
chilenos se contrasta con la forma cobarde y traicionera (en la imagen que se lee de los relatos chilenos) en que actúan los peruanos; "[Luego del estallido del fuerte] el avance hacia Arica se prosiguió con mucha cautela (...) la indignación que en la tropa producían los métodos que empleaban los peruanos, tan contrarios al modo de ser chileno, que ataca de frente y a cara descubierta, era muy grande"48.

El Relato de la víspera de la Batalla de Miraflores, corría el rumor entre las filas chilenas de una posible chance de paz y que por tal motivo se entraría a Lima solamente con el fin de firmar la paz y de ahí volver a Chile. Sin embargo el sonido de fusiles hizo prevenirse de un inminente ataque y pensar nuevamente en otra traición peruana; "con gran sorpresa de todos, se sintió un nutrido fuego de fusilería e instantes después comenzaron a llegar soldados a la carrera gritando: 'Traición!.... ¡Los cholos están atacando!'”49.

La narración de Benavides nos relata la batalla de Chorrillos y de Miraflores, en cuya descripción buscamos ver las similitudes y diferencias para con las demás sobre los mismos asuntos,

"el segundo batallón, el mío, al mando del mayor Villarreal, avanzó de frente y a poco se desplegó también en guerrillas (...) Habíamos avanzado algunos centenares de metros ¿trecientos?... ¿quinientos?... no lo sé; cuando se tocó 'fuego de avance'... a partir de ese momento las filas perdieron la uniformidad y avanzamos en aparente desorden" 50

Otro aspecto relevante de la crónica es la referencia a los peruanos:

"Del cerro que trepábamos nos hacían fuego vivísimo de artillería y fusilería, y una bandera peruana flameaba en él...

Se veía perfectamente que un valiente oficial peruano, sin esquivar su cuerpo a las balas, blandía su espada alentando a los suyos (...)

Yo admiraba la serenidad del oficial peruano que alentaba a su tropa; pero comprendiendo que si era derribado ellas se desmoralizarían, recomendaba a los soldados hacerle puntería especialmente" ${ }_{51}$

Es de notar que la valoración de Benavides por el oficial peruano, nos da a pensar en que el oficial chileno que escribe la crónica que estamos desglosando, reconoce un igual en dicho soldado (oficial, específicamente) peruano. Éste aprecio o respeto por el oficial peruano se contradice con las críticas de des-leales y traicioneros que se lanzan por los mecanismos estratégicos de los peruanos (sorpresa, emboscadas, trampas, engaños etc.).

Una vez que la lucha de guerrillas estaba a favor del ejército chileno, la llegada de la caballería en ayuda de las tropas de Chile, dieron la razón para que Benavides pudiera hacer una descripción de la soberbia, terrorífica y cuasi mitológica carga de la fuerza de ataque chilena:

"Desde donde estábamos pudimos ver como a un kilómetro hacia la izquierda de nosotros, que uno de nuestros regimientos de caballería cargaba sobre los fugitivos que por los potreros huían. 
¡Era un espectáculo imponente e impresionante!...

Entraron en correcta formación, y de pronto se dispersaron persiguiendo a los fugitivos que huían aterrorizados... Y divisábamos perfectamente cómo algunos de los derrotados peruanos corrían procurando escapar, cómo otros intentaban ocultarse tendiéndose cerca de los cierros, muralla y hasta dentro de las acequias; y cómo nuestros fornidos centauros a todos alcanzaban o descubrían, y con sólo un golpe de sus sables les destrozaban las cabezas" ${ }^{52}$.

Hasta acá en el testimonio de Benavides se reflejan las experiencias de sectores elitista y donde su reconstrucción en forma de crónica permite ver como el tiempo ${ }^{53}$ ha permeado y adaptado el lenguaje y los recuerdos haciéndolos más cercanos a una narración que contó tal cómo sucedieron las cosas. Sus recuerdos de la cotidianeidad se mantienen ya que como crónica, este relato (sin un énfasis ni cientificista ni objetivo de descubrir causalidades) nos muestra las vivencias de la Guerra, pero el tiempo ha permitido hermosear las palabras y quien sabe si también omitir, seleccionar o cambiar información.

Una vez más la ciencia del pasado pierde poder de descubrir el pasado ${ }^{54}$ y nos plantea solamente un análisis de las huellas o vestigios del pasado des-mitificando a la Historiografía como la ciencia del Pasado. Pasado al que por supuesto esta epistemológicamente imposibilitado de llegar a aprehender algo como el espacio temporal pretérito.

\section{ALBERTO DEL SOLAR. LA VISIÓN DE LA GUERRA DESDE UN DIARIO DE CAMPAÑA}

Otro testimonio que analizamos para ver la visión heroica del soldado está en el diario de campaña de Alberto del Solar. Éste testimonio es una pieza de rico contenido ya que nos detalla de forma muy precisa sus impresiones y sensaciones acerca de lo que es el soldado y la vida militar en la Guerra.

Este texto, sin embargo al igual que el de Arturo Benavides, son reconstrucciones de sus recuerdos o de sus anotaciones durante la Guerra, pero que han sufrido del "pulimento" o de la omisión voluntaria e involuntaria de la memoria una vez que ha pasado el tiempo.

En el prefacio que el autor escribe del libro señala de forma muy explícita; “Al recorrer hoy con cariño las páginas de mi diario de campaña, para entresacar de ellas las que me parecen de algún interés, no puedo menos que vacilar indeciso, pues cada uno de esos toscos y desaliñados apuntes, escritos entre las horas monótonas de una guardia nocturna o el bullicioso rumor del batallón en marcha" 55 . Precisamente lo que es de des-interés para él tal vez podría ser valiosísimo para nosotros y las corrientes historiográficas del s. XX y XXI. Pero no podemos nuevamente- acceder a esta información que quedó silenciada.

El diario de campaña narra cómo se enteraron el 23 de mayo de 1879, por telégrafo, del combate Naval de Iquique. Del Solar señala que el pueblo reaccionó 
con emoción, lágrimas y un silencio casi religioso. Prosiguió la acción de “oradores distinguidos que arengaron al pueblo, ensalzando las virtudes y el sublime sacrificio de nuestros marinos" ${ }^{56}$, seguidos de campanas, vítores y hurras en honor del capitán Prat.

En este caso puntual vamos a describir la narración de la llegada de Condell a Valparaíso contada por el otro testimonio que ya analizamos de Arturo Benavides:

“Algunos días después llegó la 'Covadonga'. Desde la mañana yo estaba con otros niños en el muelle a fin de ver, desde bien cerca, a Condell, oficiales y marinería que debían desembarcar. Cien veces se nos hizo retirar y otras tantas estábamos es las primeras gradas del muelle.

En el trayecto que Condell debía recorrer hasta la Intendencia y su casa se erigieron hermosos arcos.

Cuando Condell llegó al muelle, la emoción que experimenté no la sé describir; creí que llegaba un semidios" 57

Acá el jolgorio de Valparaíso por la llegada de Condell, y mayormente la visión mitificada que Benavides proyectó sobre Condell llamándolo semidios, son lo que nos motiva a pensar que el desarrollo mismo del conflicto fue generando con una cada vez mayor intención de convertir a los actores históricos de ese conflicto (que en realidad sólo fue una Guerra entre tres naciones por el control del Salitre) en una lucha épica.

En este caso más que centrar nuestro énfasis en lo que podría denominarse la búsqueda de la verdad, teniendo en cuenta las diferencias en ambos relatos; la importancia esta en el enfoque y como el jolgorio, la alegría y el entusiasmo de la victoria por un lado, y por el otro lado la emoción, tristeza o el dolor de la derrota heroica son claves como móviles para entender porque se barniza un hecho histórico de un lenguaje poético o mitológico.

Pero al igual que en la narración de Benavides no todo es heroicidad ni relatos de grandes hazañas. El reflejo de los pesares y dolores de la Guerra es sumamente crudo y revelador de la humanidad de los soldados chilenos.

Las alegrías y formas de olvidar el precio de la marcha por el desierto, de las agonías de batalla son también parte de estos relatos que reflejan un aspecto mucho menos heroico pero mucho más crudo, real y completo de la Guerra.

Primero es importante ver el sufrimiento por el cansancio, la sed y la aparición de la parte del ser humano que sólo se preocupa por sobrevivir. El instinto puro de cada uno de los hombres que al verse en la necesidad de poner en el filo de la navaja su vida a veces incluso hasta los imaginarios más solidamente objetivados como lo nacional, pierden fuerza:

"Y si veía en aquel momento a un soldado de mis filas caer revolcándose sobre la arena y medio loco enterrar su boca en ella para buscar instintivamente la humedad que le negaban sus quemantes entrañas, apartaba de él la vista y apretaba convulsivamente, como si fuera 
necesario defenderla, la caramayola que aún encerraba algunas gotas de esa vida, que así rehusaba a un semejante! ¡No sé, no sé si a los demás les pasaba en tales casos lo que a mi; pero yo me sentía tan frío ante el espectáculo de la muerte, tan egoísta ante el atroz sufrimiento de los que rodeaban, que temía haber perdido para siempre hasta el más insignificante impulso de un sentimiento humanitario, hasta la última fibra de un corazón de hombre!" 58

Pero no solamente es la sed lo que transforma al soldado en un ente individual donde sobrevivir es lo que cuenta, sino que también el miedo y la necesidad de afrontar y soportar la muerte es un elemento vital. El hombre lucha por su sobrevivencia y en eso el miedo como activador o inhibidor de reacciones en el momento que su vida peligra es un reflejo de la humanidad (obvia) de estos soldados, pero que la Lira popular y otras manifestaciones borra o canaliza de un forma dosificada sin mostrar la realidad y crudeza que sí esta en los testimonios ${ }^{59}$. Para ello un ejemplo:

"Difícil, si no imposible, me sería definir en este momento la impresión que sentí cuando me ví en vuelto en medio del fuego mortífero que nos diezmaba. Creo que mi primer impulso fue el de no seguir avanzando. Con sorpresa, sin embargo, me encontré en mi puesto al frente de mi mitad, un tanto desorganizada por las desigualdades del terreno y por la confusión que, naturalmente, habían introducido en todos los batallones los primeros disparos del enemigo, casi a boca de jarro"60

Pero la honestidad de reflejar en el testimonio el miedo de los chilenos, eso en sí no disminuye la intención de reflejar la heroicidad en los soldados de Chile, al contrario lo re-potencia y aumenta la necesidad de destacar al soldado por la capacidad de sobreponerse a la adversidad y el miedo. Al describir la reacción en combate del regimiento Esmeralda Del Solar describe:

"Mientras arrinconábamos al enemigo en sus trincheras, avanzando, siempre, las divisiones de retaguardia se acercaban, aunque no con la rapidez que nos hubiera convenido.

Una hora de combate contra las fuerzas mucho mayores, que se reemplazaban a medida que nuestros batallones, enardecidos por la pelea, les iban haciendo enormes brechas, agotó nuestra provisión de municiones, hasta el extremo de que algunos soldados se encontraron en el caso de pedirlas" 61

Frente al fragor del combate y a la gran distancia que separa al grupo de combate de nuestro narrador y las fuerzas de respaldo (muy alejadas) sólo les quedó una opción... sacrificarse:

"Resueltos a vender cara nuestra vidas, nos cerramos, estrechándonos firmemente y, siempre haciendo disparos, tratando de resistir el choque (...)

Envuelto en un círculo de fuego, en medio de nubes de humo, sólo sé que oí gritos y gemidos, choques y silbidos de balas. En cuanto a lo que sucedió... no lo sé: una confusión horrible de hombres que saltaban o se agazapaban, unos corriendo hacia delante, otros retrocediendo medio despavoridos (...)

Desatenta cogí un fusíl que me encontré a mis amigos pies al pasar tropezando por sobre el cadáver de un soldado horriblemente destrozado y quise hacer fuego; pero a la verdad no supe a donde dirigirlo"62 
La presente narración da cuenta de la crudeza que se vislumbra en el campo de batalla, en primer lugar, y el ardoroso deseo patriótico que encierran las palabras y la actitud de arrojo que expresa Del Solar. La "gloria" y "fama" que revistió a estos hombres - hoy en su mayoría desconocidos y olvidados por la memoria nacional- no fue obtenida si no en un ambiente donde la línea entre el vivir y el morir estaba a cada momento pendiendo de un hilo.

Sin embargo no todo el testimonio es devastador. En el correr de la misma campaña se fueron generando espacios de distracción como la organización de "congresos" o de "juicios contra una cabra"63.

También la música juega un rol importante entre las tropas (tocando algún tipo de música popular) con las guitarras que podían conseguir o escuchando a la orquesta del Ejército, deleitar el oído de los oficiales que podían distinguir la música docta que se ejecutaba:

"Un buen piano, dos o tres guitarras y otros instrumentos musicales que hacían la delicia de nuestras tardes de fiesta.

En ocasiones solíamos llevar la bande de música (...) a la terraza del magnífico chaley del señor Cornejo, y allí deleitábamos el oído con los trozos de ópera" ${ }^{44}$

Finalmente y a forma de cierre de los aspectos destacados del relato estaban el cómo vio (o se veía) la Guerra con Perú. Para los soldados chilenos era vista como una batalla ya ganada. Cuando el autor hace referencia a la denominación con la cual se le llamaba al territorio boliviano del "Chile nuevo": "El día 30 de aquel mes-ifecha memorable- tuvo lugar. Por fin, la tan esperada partida del convoy que debía conducir al Esmeralda, de 'Chile viejo' a 'Chile nuevo', como llamábamos ya al litoral boliviano" 65 .

El "Chile nuevo" al que hacía referencia, refleja un triunfalismo y una certeza (ya sea real o en broma) que propone una victoria antes de incluso comenzar las acciones militares. Esto está vinculado con las relaciones de triunfo y victoria en el pueblo chileno, pero además reflejan una expresión connotada de "intervención divina". En este sentido el trabajo de Carmen Mc Evoy sobre el discurso nacional en el alto clero chileno y en la prensa de la época muestran cómo se planteó a la beligerancia con la Alianza bajo términos maniqueos y de una "Guerra Santa"

Lo anteriormente señalado, podemos asociarlo con la entrega que los soldados buscaban en una belicosidad o al menos una necesidad de combatividad, que nos muestra que estaban preparados y gustosos a luchar. Como lo refleja una de las pocas cartas que inserta en la crónica y que tiene como fecha el 24 de febrero de 1880 dice que "la animación y el entusiasmo son grandes entre los soldados, ansiosos ya de recibir el bautismo de fuego: todos deseamos que se nos dispute el desembargo y aprontamos nuestro ánimo para imitar el arrojo de los asaltantes de Pisagua" 67 . 
En la imagen del soldado que hemos revisado, observamos lineamientos comunes sobre la gallardía chilena, el valor nacional, el fuerte exitismo en el conflicto, pero a la vez fusionado con un miedo constante a perder la vida, una visión completa de una campaña bélica donde la cotidianeidad forma una manera de sociabilidad muy, muy interesante.

\section{HIPÓLITO GUTIÉRREZ. EL RELATO DE UN SOLDADO RASO. EL TESTIMONIO DEL MUNDO POPULAR}

Las vivencias del mundo popular en la Guerra han sido estudiadas en las corrientes historiográficas actuales. En este sentido la experiencia de Hipólito Gutiérrez y la de Abraham Quiroz son representaciones de este mundo popular que se ha dado en denominar el "roto chileno" y que la Historiografía tradicional decimonónica y otras expresiones literarias del XIX y XX han construido en torno a la participación del mundo popular en la Guerra del Pacífico.

El relato de Hipólito Gutiérrez acerca de un episodio particular de la Guerra y su aptitud frente a este nos resulta ilustrativo. En su relato sobre su visión y participación en la Batalla de Tacna nos cuenta que:

"Seguimos peliando y las balas que nos caían como cuando llueve granizo y los compañeros caendo a más y mejor, saltando los cuerpos a un lado y a otro. Era tanto el cerramiento de balas que a mi me pasaban por de entre las piernas, por los sentidos, pero nada de temor, me parecía que una fier (h) ta ora una travesura" ${ }^{68}$

Otra narración interesante al finalizar la batalla es el deseo de saqueo y pillaje presente en Hipólito el cual refleja pesadumbre primero, por no poder saquear la ciudad de Tacna y segundo por no poder comer - uno de sus principales énfasis es hablar de lo bien que se come- y el cómo se hacían estas actividades en el campamento,

"bajamos para la cuidad de Tacna que se veía cerca como una legua y muchos cuerpos más y (o)tros iban dentrando 1 pueblo tiros y más tiros y nosotros también íbamos a dentrar y dentrando íbamos cuando nos volvieron para atrás. ¿Qué rabia nosotros!, cuando nos habia dicho mi General que si ganábamos laución ái los daba saqueado en Tacna"69

Tal vez como una forma de incentivar la lucha y la batalla en los soldados rasos (muchos sin mayor instrucción militar) los oficiales les prometieron la posibilidad de saquear una ciudad enemiga, pero al encontrar en el interior muchos chilenos eso detuvo al Ejército de cumplir su promesa.

En otra parte de la narración, Gutiérrez también nos muestra la humanidad del soldado chileno siendo victima del miedo y de la desesperación en el inicio de la Batalla de Chorrillos donde nos relata lo siguiente: 
"esto le estoy acabando de decir estas palabras cuando viene una granada y caye en medio de las dos filas de mi compañía que era la cuarta del $2^{\circ}$ y caeron dos soldados al suelo porque la granada rebentó y a un cabo $1^{\circ}$ que estaba en fila esteor le pegó en una pierna en una pierna y en un brazo, pero no lo hirió (...) los soldados se iban atemorizando por las granadas que estaban caendo y yo le esplicaba- no tengan miedo, hombres, avancen no más que nadien muere mientras no se le llegue la hora. Y seguimos avan(zan)do al fre (n) te bastante distante iban avanzando los nuestros dando fuego a una trincheras adonde estaban las artillerías enemigas"70

También se ha mostrado la brutalidad de la Guerra, pero a la vez la valentía y la sangre fría de la lucha. El ingreso a la Ciudad de Chorrillos refleja el hecho donde prima el uso de la lógica de sobrevivencia y no un acto heroico:

"Era la causa del que de adentro de las casas nos tiraban a traición y así que dentrábamos para dentro de las casas y se acababa con cuantos se hallaban"71

El siguiente párrafo refleja a la vez, la heroicidad y fuerza del Ejército chileno:

"De Lima llegaron como cinco mil en las máquinas y los hicieron guerra. Esos cuase los acabamos todos y los que no se mataron se cautivaron. Se cautivaron coroneles, capitanes, mayores y oficiales peruanos, en fin todos en general, y los que se podían hallar en las casas, es decir a todo el pueblo"72

El otro elemento que queremos destacar es la narración de la Batalla de Miraflores. Hipólito Gutiérrez se enfoca en el actuar del ejército chileno. Según la narración de este soldado la traición en Miraflores originada por los peruanos marcó una diferencia clásica de lo que es el soldado chileno, ejemplificado en el roto y el cholo peruano:

“ [lo que nos] hicieron estos cholos traicioneros del andar pidiendo las paces para pillarlos descuidados y mi ge (ne) ral que se confió tanto, pero como los chilenos que somos andamos a la buena si peliamos peliamos a pecho descubierto, no como estos traicioneros y maricones cholos que no andan no más que con traiciones (...) pero de nada les sirve, todo es en vano, para el chileno todo se abarraja y todo se desarma porque no hay temor ni se vuelve las espaldas, ¡viva Chile!"73

En estos párrafos podemos ver que la tónica de la construcción de identidad por medio de la diferencia entre el chileno (valiente) y el peruano (cobarde) se establece a una separación notable y que vemos se repite en más de uno de los relatos, reflejando una de las principales características del soldado chileno: Es valiente, arrojado y temerario al compararlo con el "otro". El peruano cobarde.

El mundo popular aportó con otra fuente como fue las experiencias de Abraham Quiroz, del cual no hemos extraído información al no entregar (al menos en la revisión que realizamos nosotros) ningún elemento nuevo que no apareciera en el texto de Gutiérrez. Sin embargo lo anterior es importante señalar que la relevancia de la adopción del discurso patriota por parte de Gutiérrez, su lenguaje popular y sus códigos es realmente significativa a la hora de aportar en la investigación. 


\section{EVARISTO SANZ. EL TESTIMONIO EN CARNE PROPIO DEL VALOR Y EL "PAGO DE CHILE"}

Si bien ya hemos constatado las fuertes narraciones de los soldados que nos cuentan el sufrimiento y padecimiento humano que ellos como personas - sin tomar ningún partido sobre ellos- tuvieron que pasar nos llama la atención acerca de lo álgido que fue el mantenerse vivo en una travesía como la del desierto.

Sin embargo el sufrimiento más crudo talvez sea el del "pago de Chile" a posterior y el del dolor de haber servido al país en busca de una retribución merecida y correspondida ya que ellos habían arriesgado su vida por la patria enfrentándose en terreno adverso contra el enemigo.

En este sentido es que obtiene significatividad dos nuevos testimonios que a la hora de redactar este artículo hemos podido encontrar y que nos permiten complementar lo que ya veníamos trabajando desde la elaboración de la tesis de grado que dio nacimiento a este tema.

El primero de ellos es el testimonio de Evaristo Sanz quien nos plantea cómo sufre la decepción de no haber conseguido el reconocimiento y el ascenso que él esperaba por haber servido a su patria y arriesgar su vida en el campo de batalla. Él nos relata con estas palabras la experiencia:

“Hoi que la guerra ha terminado, hoy que, disipado el humo de los combates, los hombres cuentan los guerreros i pesan sus acciones i méritos conquistados por los ascensos conseguidos, siento subir a mis mejillas el rubor de la vergüenza al tener que contestar a las preguntas de todos: no he conquistado nada, ni un solo galon; salí de subteniente, de subteniente he quedado después de haber hecho toda la campaña (...) para el porvenir solo puedo legarles una espada que, aunque desconocida, supo siempre mantener alta la honra de Chile"74

Nuevamente hay en este texto que pesquisamos el asunto de los saqueos tan típicos durante los conflictos bélicos y que forma parte de un mecanismo de financiamiento de las campañas que data de muy antiguo. Más que analizar el hecho de la pertinencia moral o no del efecto, nos interesa ver cómo el saqueo produce intereses de apropiación del botín de soldados en toda la Jerarquía. Sin necesidad de negar el hecho, nos permite vislumbrar primero que todo que la Guerra - y como ya hemos visto en la tónica del presente artículo- no es un enfrentamiento entre seres "especiales" ni mucho menos no sujetos a deseos que la Historiografía nacional idealizada talvez quisiera borrar en el mejor de los casos y de no poder, narrarlos en voz baja para que no sean oídos por la mayoría.

La situación puntual que nos cuenta Evaristo Sanz es de cómo su superior en colusión con un subalterno (de apellido Guevara) con el cual se hacen del botín completo ya Evaristo nos narra que cuando él les informa acerca de la desaparición del botín ambos parecían no sorprenderse, hasta que Evaristo Sanz enfatiza en sus sospechas de que el robo fue planeado por un superior del soldado que efectuó el robo: 
"Sin duda la cólera que me ahogaba [a Evaristo Sanz] salió a mis ojos al pronunciar estas palabras [la hipótesis del envió por parte de un superior a aquel soldado a robar]. Lo cierto es que el comandante Echeverría, mi jefe, cambió de color, tiñéndose de verde sus mejillas, un sudor abundante bañó su frente, i sus miembros se ajitaron con el temblor del miedo. ¡El, el primer jefe del cuerpo con miedo delante de un subteniente! ${ }^{75}$

El mismo Evaristo cuenta como el comandante corrió el rumor de que él mismo Evaristo había acaparado con todo y corrió el rumor del robo. ¿Quién contó la verdad? Nuestro artículo no busca descubrir la verdad sino contemplar como un "glorioso ejercito" en su cotidianeidad representa una variopinto de contradicciones, que lo elevan a la calidad de realidad Histórica, o sea, contradictoria y no manqueado, como la Historiografía nacional.

Las implicancias de elementos propios de la cotidianeidad de la vida (miedo, dolor, robos, saqueos, violencia entre "compatriotas") dan un sustrato humano y real a lo que fue la Guerra del Salitre. Un conflicto entre sujetos históricos, chilenos, de diversas clases sociales (algunos o talves la mayoría con un verdadero amor a su patria) pero que en ningún momento fueron simples reducción simbólicas del bien, resumen de todos los valores que nos auto-conferimos en el discurso nacional construido (o construidos) desde las elites dominantes, los sectores medios ${ }^{76}$ y populares; el soldado chileno fue una amalgama de valores dispares que mostró toda su potencialidad histórica en que sus fuentes nos mostraron que no fue un ejemplo de virtud -únicamente- sino un completo contradictor de la homogeneidad que la Historia oficial ha construido.

El calor y la sed fueron grandes enemigos de la tropa - en cualquier parte lo son- y causaron sublevaciones y crisis. Sanz acá nos cuenta una de ellas: " Tan grande sería su sufrimiento, que casi la mitad de la división tomando sus armas de los pabellones en uno de los descansos del día 15 huyó sublevada al Valle de Moquegua en busca de agua"77.

La solución de comandante fue ordenar el cierre del paso por parte del Batallón Bulnes y amenazar con disparos que de avanzar serían baleados por sus propios compañeros. Un clima para nada calmo ni perfecto en pleno mes de marzo de 1880.

La descripción que nos hace sobre la batalla de Chorrillos es de una fuerza y de una gran heroicidad demostrada por el Ejército nacional que instaló en el corazón de Perú sus tropas con gallardía y heroísmo sublime. Sin embargo su relato de su actuación nos posiciona en otro aspecto mucho menos vistoso pero más significativo a nuestros ojos: "[luego de recibir una bala cerca del cuerpo] un instante mis nérvios se crisparon i tuve miedo. Más la idea de que era soldado de Chile [...] me hicieron reaccionar i resignado me eché en brazos del destino"78.

Otro evento relevante relatado por nuestra fuente tiene que ver con el desorden impartido por soldados del mismo Ejército que usó más de algún destrozo y "caos": 
"Si el combate con las fuerzas enemigas había terminado, en Chorrillos segui tan nutrido o mas que ántes el fuego de fusilería sin saberse a quien se disparaba: era parte de nuestra tropa que, embriagada de triunfo i de los esquisitos licores [...] hacíanse fuego entre sí mismo o [...] el primero que pasaba"79

Junto con lo anteriormente señalado, resulta interesantísimo factor de análisis, la necesidad de amigos para conseguir las cosas en Chile y la distinción "clasista" o segregacionista que hoy en día tanto se nos reprochan como sociedad, en el siglo XIX están plenamente presentes y son parte del cotidiano de la forma de accionar del país.

Ya José Victorino Lastarria en su texto "Manuscrito del diablo", Diego Portales en sus cartas o más tarde el poeta Vicente Huidobro en su "balance patriótico" cimentarían una crítica o una caracterización psico-sociológica del carácter chileno o de lo que, a su juicio, nos define como sociedad.

En pocas partes hemos podido (como investigadores) contemplar este tipo de referencias visearles, desde elementos castrenses, referirse a la situación del país y específicamente de la "inmaculada", gloriosa institución militar. Sanz señala: "Yo creía que para ascender bastaba solo el valor en los campos de batalla, la buena conducta en las guarniciones i campamentos i la instrucción militar, pero ese diálogo me enseñó que aun se necesita algo más [...] tener un hermano que sea amigo del jefe, i esto es lo esencial" $"$.
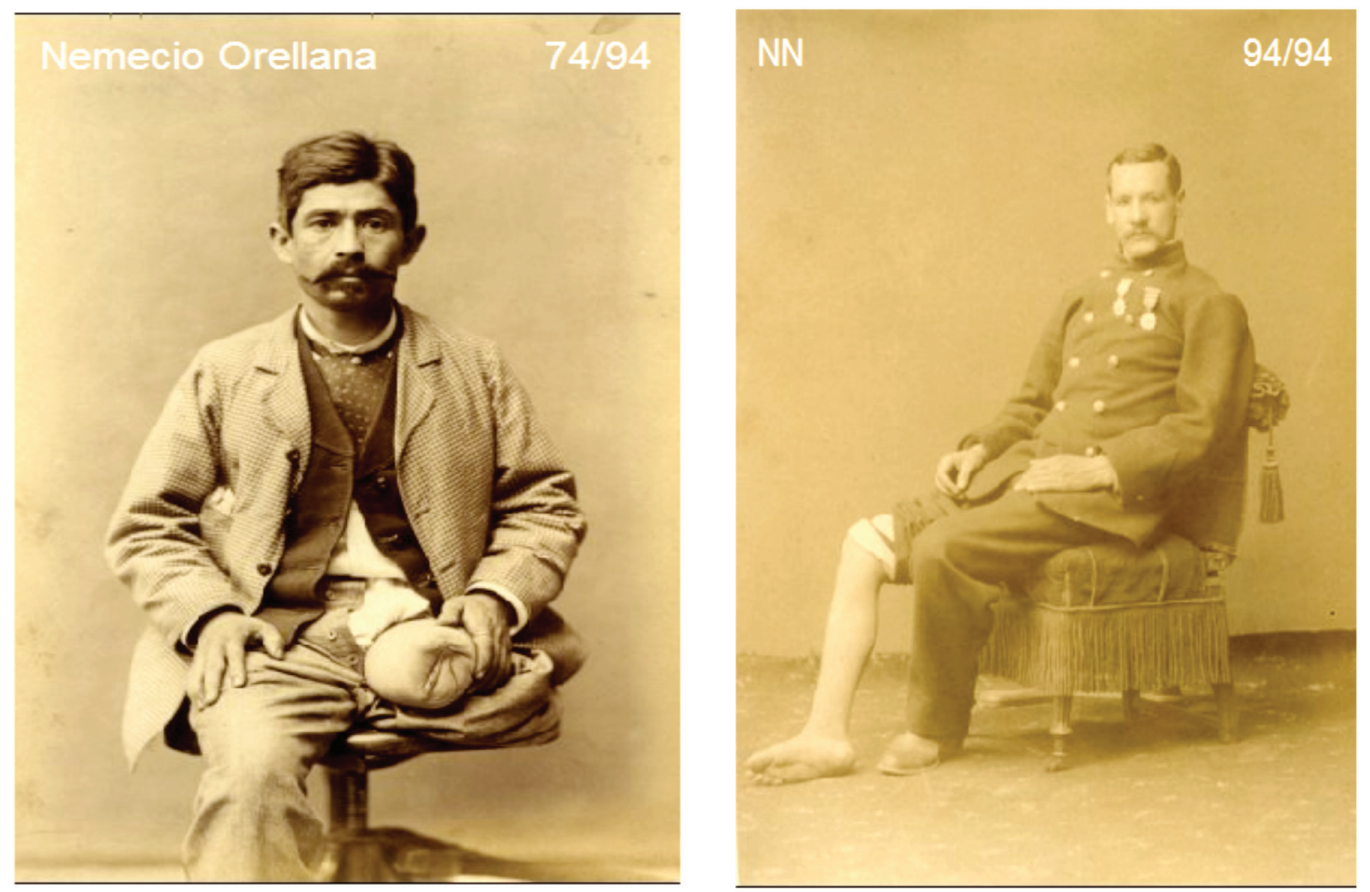

Figura 3 y 4. El Precio de la Guerra. Acá podemos ver el precio físico que pagaron un soldado llamado Nemecio Orellana y un N.N. Imaginemos las complicaciones de sobrevivir y llevar una familia siendo mutilado y agregándose el hecho de no tener apoyo económico del Estado chileno. Dicha característica se llamará "El Pago de Chile"

Fuente: http://www.guerradelpacifico1879.cl/fotos_mutilados/fotos_mutilados.html 
Otro error que descubre es sobre algo muy de moda también hoy y es el discurso unitario de lo nacional: “¡Otro error en que yo estaba i del que salí ese día! Pensaba que para servir a la Patria tanto daba un cuerpo como el otro, siendo que en realidad no es así, como lo aprendí entonces"81.

Si bien finalmente el relato de Sanz termina en el retiro y la escacez de trabajo y la precariedad (al perder el sueldo de subteniente) y el total desamparo en que la Patria (por la que se arriesgó) y el Ejército (al cual sirvió), lo dejaron no quedó para él más que resignarse. Un cruel pago, pero del cual Sanz no fue la única victima.

El testimonio de José Clemente Larraín en sus inicios confirma una visión de la Guerra que el historiador William Sater en su libro ya anteriormente citado puntualiza ${ }^{82}$. Como tanto sectores castrenses como la misma oposición conservadora hacia el Presidente Aníbal Pinto estableció en culparlo a él de la pasividad o los problemas que en un comienzo tuvo la estrategia chilena.

Larraín como testigo de la época nos lo plantea de la siguiente manera: "El pueblo estaba poseído, y acalló sus aspiraciones políticas para uno contra el enemigo extraño. La Cámara y el Senado, en la mayor parte de sus miembros, constituyeron el alma que dio vida al Gobierno" $"$.

Lo que podemos inferir es cómo la incompetividad del gobierno fue un móvil de la incapacidad de actuar y que finalmente fue el poder Legislativo (que ya en este periodo tenía un conflicto de poder con el "presidencialismo") el que movilizó a actuar al que parece ser un gobierno liberal poco "patriota".

Como hemos constatado en el análisis de esta fuente la principales líneas de relato pasan fundamentalmente por los mismos aspectos que los demás relatos por lo tanto resultaría mucho más redundante citar cosas ya dichas como el padecimiento, el dolor, la sed, el miedo a morir o los problemas típicos del campo de batalla. Resulta innecesario.

\section{LA GUERRA, LOS TESTIMONIOS Y LAS IMPRESIONES. CONSIDERACIONES FINALES.}

A modo de cierre (momentáneo) de esta investigación nos queda señalar que hemos intentado establecer un nexo - no nuevo ni menos definitivo- entre la idea de Nación, Guerra e Identidad nacional. Éste tópico no fue lo fundamental de nuestro artículo, pero considerábamos indispensable establecer los contextos teóricosociales desde donde analizamos en primer lugar la Guerra del Pacífico, y específicamente en ella, los testimonios de sus actores más importantes. Los soldados.

Desde esta perspectiva fue la necesidad de abordar la Historia desde los testimonios de los propios actores. El valor de los testimonios en la Historiografía actual ha sido re-potenciado, pero se han postergado muchas veces por la Historia 
"cuantitativa" y serial o por el rescate de testimonios de los sectores subalternos rescate más que válido- pero que si se transforma en el único testimonio necesario o válido para el rescate histórico, empobrece la visión del pasado.

Es por esto que en primer lugar el testimonio de la Guerra del Pacífico ha pervivido en destacar al soldado y al héroe (en el sentido histórico y no mitológico) como un elemento importante del conflicto y donde podemos explorar en su historicidad.

En segundo lugar el testimonio ha sacado a la luz la humanidad del soldado y ha pervivido en no sobredimensionar la heroicidad que no es, reiteramos, mitológica. Junto a los relatos de valentía han convivido verdaderos rasgos de historicidad y cotidianeidad como miedos, infecciones, alegrías y resquemores de los soldados. De esta manera los rasgos de cotidianeidad no se han perdido ni siquiera en aquellos documentos y relatos que hemos analizado y que no representan una narración realizada en un tiempo muy cercano al conflicto - por ejemplo escritos varios años después del conflicto - o aquellos que han demostrado la selectividad y omisión voluntaria del autor, en un proceso de "limpieza" del relato para poder ser publicado (caso de Alberto del Solar), pero donde noción de su propio "devenir histórico" no se ha perdido o sólo se han cambiado algunos relatos, tiñéndolos con una mayor elegancia o con comparaciones con seres y actuaciones mitológicas que no afectan en demasía la narración.

El reflejo humano del padecimiento sin la mitificación es un rescate sumamente importante de la imagen que realmente querían (o al menos pensaban) que proyectaban los soldados, sin una necesidad de mostrarse invulnerables. La intención de los testimonios es narrar lo que vivieron, nada más ni nada menos.

La Historia como reconstrucción de las "huellas del pasado" o de los vestigios que desde un tiempo no-presente perviven y nos permiten acceder a "interpretar" este pasado, tiene directa relación con los testimonios y con nuestro trabajo ya que no nos interesaba puntualmente descubrir la "verdad" sobre el pasado sino más bien las subjetividades implícitas en las omisiones, olvidos, mitificaciones (o las no-mitificaciones), las inexactitudes o representaciones de su experiencia en la Guerra.

Si bien no hemos podido profundizar en la Guerra del Pacífico a cabalidad como quisiésemos, sí es claro que las críticas de soldados como Sanz y Larraín representan una diametral diferencia de las de Benavides o Hipólito del Solar ya que estos últimos representan en su misma biografía personas de ascendencia mesocrática y que llegaron a donde estaban por medio de sus influencias familiares. Lamentablemente tampoco hemos podido extender nuestra investigación para llegar a establecer un análisis biográfico de los actores (contextual) para comprender las diferencias de criterios ya que resulta llamativo que no sean expuestas las mismas críticas en los distintos documentos y que se explicarían en la divergencias social y contextual del cómo y el por qué cada uno estaba peleando en la Guerra. 
Además de lo ya señalado creemos que una aproximación teórica y metodológica en estos contenidos resulta necesaria, importante y adecuada para potenciar las miradas sobre estas fuentes, que reconocemos han sido abordadas desde una investigación de orden exploratoria y que necesariamente pasa por entender que el trabajo sobre la Guerra del Pacífico es un tema que necesita ser abierto a otras formas de estudio que superen lo político-bélico. En ese contexto queda este artículo como un pequeño aporte a mejorar aquello.

Queda además pendiente un análisis mayor entre líneas de los documentos analizados, una metodología comparada y un enriquecimiento de esta investigación con otro tipo de documentos (archivos judiciales, cartas, fuentes peruanas y bolivianas) que permitan complementar lo que intencionalmente movilizó la redacción de este artículo; conocer las subjetividades históricas volcadas en el documento y que nos permitan comprender lo que pasaba por las mentes de los militares chilenos, y que alcanzó a ser conocido una vez se expresó en papel. Este fenómeno (testimonios subjetivos, pero en forma escrita) son suficientemente rico en historicidad como para que valga la pena estudiarlo.

\section{CITAS Y NOTAS}

* El presente artículo tiene su origen en el segundo capítulo de la tesis para optar al grado de Licenciado en Historia de la Universidad de Concepción titulada "El soldado chileno de la Guerra del Pacífico: Entre sujeto histórico y mitificación arquetípica”. Si bien la investigación ha tenido una complementación con el tiempo, la estructura general se basa en los planteamientos de dicha tesis.

1 En este sentido las tesis de autores como Gellner, Anderson y principalmente Hobsbawm han consistido fuertemente en asociar la idea de Estado - nación a un criterio liberal, modernizador y laico al cual otros autores cuyo principal autor es Adrián Hastings. Éste autor puntualiza entre sus ideas centrales el cómo la identidad nacional puede verse reflejada en sociedad pre-modernas o inclusive bajo criterios no únicamente liberales laicos, sino en sociedades fuertemente conservadoras o religiosas (judaísmo). Para mayor información véase. Hastings, Adrián, La construcción de las nacionalidades: etnicidad, religión y nacionalismo, Madrid, [Cambridge University Press], 2000, pp. 272.

2 Tesis principal de la Historiografía hispanista basada principalmente en Mario Góngora. Las ideas de éste autor son básicamente donde la tradición bélica y guerrera del territorio chileno - cuando era una Gobernación, constituyente del Virreinato del Perú- llevaron a formar un Ejército estable y las constantes luchas contra los mapuches, los españoles, los peruanos y bolivianos han formado una especie de "identidad" belicista de nuestro país. Esta tesis ha sido contrastada y refutada por autores como Sergio Villalobos y la Historia Social postdictadura, que han demostrado por un lado que la vida colonial del país y la lucha contra los mapuches no fue una "guerra a muerte" constante y gozó de muchos tiempos de paz e intercambio comercial en la llamada "frontera". Por otro lado trabajos como el de Jorge Larraín y Carlos Maldonado han sistematizado una confrontación a estas hipótesis. El primero, la idea 
de la construcción mítica de la identidad nacional "belicista" y el segundo ataca los vínculos entre la Historia nacional y la Historia del Ejército que han construido un mito del "Ejército jamás vencido" durante el siglo XIX. Véase Góngora, Mario, Ensayo Histórico sobre la Noción de Estado en Chile en los siglos XIX y XX, Santiago, [Editorial Universitaria], 2003, pp. 431; Centro de estudios Miguel Enríquez (CEME), Archivo Chile. Documentación de Historia político social y Movimiento popular contemporáneo de Chile y América Latina, Maldonado, Carlos, El Ejército chileno en el siglo XIX. Génesis histórica del `ideal heroico`1810-1885, www.archivochile.com/Poder.../ffaa_y.../PDffaasobre0015.pdf (acceso diciembre 20, 2010); Villalobos, Sergio, La vida Fronteriza en la Araucanía: El mito de la Guerra de Arauco, Santiago, [Editorial Andrés Bello], 1995, pp. 215.

3 La Guerra del Pacífico es fundamentalmente un nexo y un conflicto que diferencia la participación del pueblo (sectores populares) frente a conflictos de esta naturaleza. Haciendo un estudio comparativo entre la "fervorosidad" del pueblo en la Guerra Contra la Confederación Perú Boliviana y la Guerra del Pacífico. En esta última el elemento patriótico popular se manifestó con mayor énfasis.

4 Pinto, Julio. ¿Patria o clase? La Guerra del Pacífico y la reconfiguración de las identidades populares en el Chile contemporáneo. Contribuciones Científicas y Tecnológicas, 116 (1997), pp. 49.

5 Osorio, Cecilia, "Ser hombre en la pampa. Aproximación hacia los rasgos de masculinidad del peón chileno en las tierras del salitre, 1860-1880". en [Colectivo Oficios varios], Arriba quemando el sol. Estudios de Historia social Chilena: Experiencias populares de trabajo, revuelta y autonomía (1830-1940), [LOM Ediciones], 2004, pp. 91-94.

6 Véase Pinto, Julio y Valdivia, Verónica, ¿Chilenos todos? La construcción social de la nación (1810-1840), Santiago, [Lom Ediciones], 2009, pp. 7-20.

$7 \quad$ Pinto, Julio. ¿Patria o clase?, pp. 51.

8 Tema que irá cambiando a medida que se va llegando a los finales del siglo XIX y acercando al siglo XX. Recordemos que la relación del grupo de poder de la aristocracia chilena (mal llamada aristocracia) o el sector estanquero-conservador y el grupo liberal (a mediados del s. XIX) van a generar un fuerte vuelco europeizador de sus costumbres y de sus gustos, que van a no sólo a separarlos en cuanto a oligarquía (grupo minúsculo que contiene el poder), y a relacionar la "cosa pública" con la "cosa privada" (el ejemplo del salitre es clave) sino que también en cuanto a que, este grupo de elite van a separar su gusto "hispano" por la chingana por la sofisticación del teatro, la ópera y los viaje a Francia. Véase Vicuña Urrutia, Manuel, La Oligarquía chilena como actor urbano del siglo XIX, Santiago, [Impresos Universitaria S.A.], 1996, pp. 11-14, 86-104.

9 Véase Ortega, Luis. "La política, los empresarios y los orígenes de la Guerra del Pacífico”, Santiago [FLACSO], 1984, pp. 1-4.

10 Para el tema del arquetipo consúltese Jung, Carl, Arquetipos e inconciente colectivo. Barcelona, [Paidos], 1970, pp. 182; Eliade, Mircea, El Mito del eterno retorno: arquetipos y repetición. Madrid, [Alianza], 1989, pp. 174; Campbell, Joseph. El héroe de las mil caras: sicoanálisis del mito, México D.F., [Fondo de Cultura Económica], 1959, pp. 372. 
11 No está de más especificar que las ideas de bien y mal corresponden a determinaciones basadas principalmente en el discurso nacionalista chileno. La contraparte peruana o boliviana invierten los roles positivos y negativos. Para una idea de lo que es la "Historia" como territorio discursivo justificatorio de la victoria o la derrota véase León Portilla, Visión de los Vencidos: Relaciones indígenas de la Conquista. México, [UNAM], 2007, 312 pp.

12 Topolsky, Jerzy, Metodología de la Historia, Madrid, [Ediciones Cátedra], 1973, pp. 298.

13 Topolsky, Jerzy, Metodología, pp. 299.

14 No es menester abarcar el problema de las fuentes en este artículo, pero sí es relevante señalar que el problema es epistemológico. Lo que se ha entendido por objeto de estudio de la disciplina a sufrido modificaciones (positivismo-historicista, historia cuantitativa, historia total, social etc., etc.) por ende lo que se ha entendido como fuente para responder a los "vacíos" o problemas históricos ha sido llenado de diversas maneras.

15 Topolsky, Jerzy, Metodología, pp. 303.

16 Es importante entender que nuestro presente artículo responde a ser una parte de la tesis para obtención del grado de licenciado de quien escribe titulada "El soldado chileno de la Guerra del Pacífico. Entre sujeto histórico y mitificación arquetípica", donde los testimonios son enriquecidos con las Liras populares de la época para el estudio del objeto en cuestión.

17 Bloch, Marc, Apología de la Historia o el oficio del historiador. México, [FCE], 2001, pp. 84.

18 Bloch, Marc, Apología de la Historia. pp. 85. En esto cobran sentido las palabras de Herodoto sobre las motivaciones que tuvo para escribir sus 9 libros de la Historia.

19 Bloch, Marc, Apología de la Historia. pp. 86.

20 Para una idea acabada y bien trabajada sobre San Agustín consultar Ricoeur, Paul, Tiempo y Narración tomo I, México, [Siglo XXI], 2000.

21 Le Goff, Jacques, El Orden de la memoria. El tiempo como imaginario, Barcelona, [Paidós], 1991, pp. 228.

22 Como ejemplos está el Monumenta Germaniae historica y el Monumenta historiae patriae.

23 Esto también nos llevaría a una nueva visión del rol del historiador, en ese sentido tomaríamos las idea de Bloch del historiador como juez o como científico, por ende si debe juzgar o comprender Pero no es el tema central en este trabajo.

24 Hemos señalado el problema de la "nueva" tendencia historiográfica de la Historia del Tiempo Presente (H.T.P), principalmente en la corriente de Julio Aróstegui. En éste sentido la idea de la Historia vivida, el testimoniar (o sea una metodología) de potenciar el recuento, la recopilación de documentos que reconstruyan el "presente" epistemológico (verdadero tiempo de la Historia entendida como devenir humano). En este caso Aróstegui puntualiza el trabajo de Hobsbawn "Historia del siglo XX", como un ejemplo de este tipo de Historia. En él el gran historiador británico, plasma no sólo un juicio histórico sino su testimonio vivencial a lo largo del siglo XX (corto como él lo denomina en su obra). Para mayor información Véase, Aróstegui, Julio, Historia vivida: sobre la Historia del presente, Madrid, [Alianza], 2004. 
25 No es nuestro deseo profundizar en el problema de la Memoria. Este concepto (ambivalente en cuanto a sus significaciones en las distintas ciencias sociales y/o naturales) representa un problema epistémico complejo. Sin embargo desde la Historiografía podemos considerar la memoria y la Historia como dos conceptos diametralmente distintos. Dentro de estos la ida del olvido como falencia y/o como mecanismo propio de la construcción del recuerdo y la memoria son un elemento divisorio y complejo a la hora de analizar estos temas. Para más información Véase Le Goff, Jacques, El Orden de la Memoria, pp. 228-231.

26 Según Cardoso y Brignoli el historicismo positivista buscaba comprender el pasado conciente de tal o cual época. Para la Historia científica cuantitativa del siglo XX lo que es estructural e inconciente a los sujetos históricos del proceso en cuestión es más relevante. Véase Cardoso, Ciro y Pérez Brignoli, Héctor. Los Métodos de la Historia. Introducción a los problemas métodos y técnicas de la Historia demográfica, económica y social, Barcelona, [Editorial Crítica], 1986, pp. 20.

27 Cardoso, Ciro y Pérez Brignoli, Héctor. Los Métodos de la Historia. pp. 25-38.

28 Fraser, Ronald, "Historia Oral, Historia Social”. Revista Historia Social, nº 17, (1993) pp. 132.

29 Suárez, Federico, La Historia y el método de investigación histórica. Madrid, [Rialp], 1987, pp. 173.

30 Baeza, Manuel Antonio, Los Caminos de la realidad social. Ensayo de sociología profunda sobre los imaginarios sociales. Santiago [Ril editores], 2000, $158 \mathrm{pp}$.

31 Schwarzstein, Dora, "Memoria e Historia”. Desarrollo Económico, Vol. 42, N 167, (2002) pp. 472.

32 Schwarzstein, Dora, "Memoria e Historia". pp. 475.

33 Schwarzstein, Dora, "Memoria e Historia". pp. 477

34 Guzmán, Cornelio, "Relato del cirujano de la Esmeralda Dr. Cornelio Guzmán”. En Pelayo, Mauricio, La Guerra del Pacífico los héroes olvidados, http://www.laguerradelpacifico.cl/ Relatos/Iquique/Relatos.htm (acceso, diciembre 15, 2010)

35 Guzmán, Cornelio, "Relato del cirujano".

36 Sánchez, Francisco Segundo, "Carta del 16 de Junio de 1879 del Teniente Francisco Segundo Sánchez a Carlos Sánchez”. En Pelayo, Mauricio, La Guerra del Pacífico los héroes olvidados http://www.laguerradelpacifico.cl/Relatos/Iquique/Relatos.htm (acceso, diciembre 15, 2010).

37 Sánchez, Francisco Segundo, "Carta del 16 de Junio".

38 Sánchez, Francisco Segundo, "Carta del 16 de Junio".

39 Historia no en el sentido disciplinar de Historiografía.

40 Benavides, Arturo. Seis años de vacaciones: recuerdos de la Guerra del Pacífico, 18791884, Santiago, [Imprenta Universo], 1929, pp. 38. 
41 Donoso, Carlos y Couyoumdjian, Juan Ricardo, "De soldados orgullosos a veterano indigente. La Guerra del Pacífico", en [Rafael Sagredo y Cristian Gazmuri (ed.)], Historia de la vida Privada en Chile. El Chile moderno. De 1840 a 1925, Santiago, [Taurus], 2005, pp. 246.

42 Véase Rodríguez, Andrés. "Forjar y forzar identidades nacionales. El reclutamiento militar durante la Guerra del Pacífico en el mundo rural" Pensamiento Crítico. Revista digital de Historia, núm. 1 (2001): 1-25, http://www.pensamientocritico.cl/index.php?option=com_ content\&view=article\&id=7: forjar-y-forzar-identidades-nacionales-el-reclutamiento-militar-durante-la-guerra-del-pacifico-en-el-mundo-rural\&catid=35:no-1\&Itemid=60 (acceso abril 15, 2011).

43 Benavides, Arturo. Seis años de vacaciones, pp. 65.

44 Benavides, Arturo. Seis años de vacaciones, pp. 69.

45 Benavides, Arturo. Seis años de vacaciones, pp. 72.

46 Benavides, Arturo. Seis años de vacaciones, pp. 72.

47 La narración de Benavides muestra como el fracaso de la operación de emboscada y asalto a los fuertes cercanos al Morro en la que él iba participando ya que el Ejército peruano tenía presupuestado que esto sucedería y se prepararon dinamitando todo el lugar para que una vez dentro la división nacional, perecieran todos con la explosión. El problema según narra Benavides fue la premura con que actuó el Ejercito peruano en dichos fuertes que por miedo huyeron demasiado antes haciendo estallar los fuertes uno o dos minutos antes de que los chilenos pudieran entrar en ellos.

48 Benavides, Arturo. Seis años de vacaciones, pp. 92. El énfasis es nuestro.

49 Benavides, Arturo. Seis años de vacaciones, pp. 141.

50 Benavides, Arturo. Seis años de vacaciones, pp. 128.

51 Benavides, Arturo. Seis años de vacaciones, pp. 128

52 Benavides, Arturo. Seis años de vacaciones, pp. 131. Énfasis es nuestro.

53 Éste testimonio no es la edición de un diario de batalla o crónicas de la época, sino una reconstrucción que hace Benavides pasado mucho tiempo de la Guerra

54 Véase. Ricoeur, Paul, Tiempo y Narración, México, D.F., Siglo XXI, 2000, Vol. 1 y Le Goff, Jacques, El orden de la memoria. El tiempo como imaginario, Buenos Aires, [Paidos], 1991, pp. 275.

55 Del Solar, Alberto, Diario de Campaña, Buenos Aires, [Editorial Francisco Aguirre], 1967, Pág. xiii.

56 Del Solar, Alberto, Diario de Campaña, pp. 27.

57 Benavides, Arturo. Seis años de vacaciones, pp. 16.

58 Del Solar, Alberto, Diario de Campaña, pp. 104-105. 
59 Para el tema de la Lira consúltese la amplia Bibliografía existente. Góngora, María Eugenia, "La poesía popular chilena del siglo XIX". Revista Chilena de Literatura, 51 (1997), pp. 5-17; Lenz, Rodolfo, La poesía popular impresa en Santiago de Chile, contribución al folklore chileno. Santiago, [Editorial desconocida], 1894, pp. 511-622; Lizana, Desiderio, Cómo se canta la poesía popular. Santiago, [Imprenta Universitaria], 1912, pp. 73; Navarrete, Micaela, Balmaceda y la Lira Popular 1886-1896. Santiago, [DIBAM], 1993, pp. 126; Palma, Daniel, “'La ley pareja no es dura' representaciones de la criminalidad y la justicia en la lira popular chilena". Revista Historia, 1, 39 (2006), pp. 177-229; Palma, Daniel, "Letras Pililas en la Prensa chilena 1875-1898". Contribuciones científicas y tecnológicas, 130 (2002), pp. 133-147; Salinas, Maximiliano (et al), El que ríe último... caricatura y poesías en la prensa humorística chilena del siglos XIX. Santiago, [Editorial Universitaria], 2001, pp. 291; Salinas, Maximiliano, "Comida, música y humor. La desbordada vida popular", en [Rafael Sagredo y Cristian Gazmuri (ed.)], Historia de la vida Privada en Chile. El Chile moderno. De 1840 a 1925, Santiago, [Taurus], 2005. pp. 85-117; Salinas, Maximiliano, Canto a lo Divino y Religión del Oprimido en Chile. Santiago, [Ediciones Rehue], 1991 pp. 332; Tala, Pamela, "La construcción de la identidad nacional en la lira popular: los versos de Rosa Araneda”. Revista Chilena de Literatura, 58 (2001), pp. 95-116.

Del Solar, Alberto, Diario de Campaña, pp. 136-137.

Del Solar, Alberto, Diario de Campaña, pp. 40.

Del Solar, Alberto, Diario de Campaña, pp. 142-143.

63 Por la extensión de estos aspectos no los citaremos pero mencionaremos lo que significan. Los congresos nacionales eran representaciones que los soldados iban realizando de las sesiones del Congreso Nacional y en las cuales las risas y formas de olvidar la presión llevaban a que actuaran de forma infantil. Por otro lado la narración de Alberto del Solar sobre el juicio contra la mascota del batallón Esmeralda (una cabra) para poder comérsela a pesar de que esta fuera la mascota y donde el célebre Ignacio Carrera Pinto las hizo de personificación del hambre en el juicio. Estas dos formas distensión bastantes llamativas de diversión.

Del Solar, Alberto, Diario de Campaña, pp. 115.

Del Solar, Alberto, Diario de Campaña, pp. 36.

Véase Mac Evoy, Carmen. "De la mano de Dios. El nacionalismo católico chileno y la Guerra del Pacífico, 1879-1881”. Revista Histórica, 28, 2 (2004), pp.108, 119.

Del Solar, Alberto, Diario de Campaña,pp. 74.

Gutiérrez, Hipólito, Crónica de un soldado de la Guerra del Pacífico, Santiago, [Del Pacífico], 1956, pp. 54.

69 Gutiérrez, Hipólito, Crónica de un soldado, pp. 56.

70 Gutiérrez, Hipólito, Crónica de un soldado, pp. 72-73. El énfasis es nuestro.

71 Gutiérrez, Hipólito, Crónica de un soldado, pp. Pág. 77.

72 Gutiérrez, Hipólito, Crónica de un soldado, pp. Pág. 77. 
73 Gutiérrez, Hipólito, Crónica de un soldado, pp. Pág. 83.

74 Sanz, Evaristo, Hojas sueltas de un diario de campaña o reminicencias de la Guerra del Pacífico 1879-1883, Santiago, [Imprenta de la Librería Americana], 1883, pp. 4

75 Sanz, Evaristo, Hojas sueltas, pp. 12.

76 El fenómeno del nacionalismo racista de fines del siglo XIX e inicios del s. XX representó una reconstrucción desde los sectores mesocráticos de un énfasis del lo mestizo y que construyó sus planteamientos de lo nacional desde su sector o clase social. Nicolás Palacios y "raza chilena" o Roberto Hernández con "el roto chileno" representan muy bien esta característica.

77 Sanz, Evaristo, Hojas sueltas, pp. 14.

78 Sanz, Evaristo, Hojas sueltas, pp. 20.

79 Sanz, Evaristo, Hojas sueltas, pp. 21.

80 Sanz, Evaristo, Hojas sueltas, pp. 27.

81 Sanz, Evaristo, Hojas sueltas, pp. 27.

82 William Sater ha sido uno de los historiadores que de mejor manera ha aportado a un reestudio y una mirada diferente al conflicto entre chilenos, peruanos y bolivianos. En sus libros destaca como la incompetencia del alto mando, sobre todo de Escala y de William Rebolledo - este último pensando más en una estrategia política para ser Presidente y con una mesura que rayaba en la inacción- llevaron a los primeros fracasos de Chile (captura del Rímac, fracaso del ataque al Callao y pérdida del bloqueo de Iquique y las andanzas de Huáscar en agua chilenas). A todo esto se debe sumar la animadversión pública que canalizó el conflicto y culpó de esto al Presidente.

83 Larraín, José Clemente, Impresiones y recuerdos sobre la campaña al Perú y Bolivia, Santiago, [Editorial desconocida], 1910, pp. 26.

\section{ACERCA DEL AUTOR}

David Angelo Coronado Canales: Universidad de Concepción. Bachiller en Humanidades Universidad de Concepción. Licenciado en Historia Universidad de Concepción. 